\title{
A Regime Switching Skew-normal Model of Contagion*
}

\author{
Joshua C.C. Chan ${ }^{\wedge} \%$, Renée A. Fry-McKibbin\%,\# and Cody Yu-Ling Hsiao ${ }^{\S} \%$ \\ ${ }^{\%}$ Centre for Applied Macroeconomic Analysis (CAMA) \\ \# Crawford School of Public Policy, Australian National University \\ Economics Discipline Group, University of Technology Sydney \\ $\S$ School of Business, Macau University of Science and Technology
}

October 2017

\begin{abstract}
A flexible multivariate model of a time-varying joint distribution of asset returns is developed which allows for regime switching and a joint skew-normal distribution. A suite of tests for linear and nonlinear financial market contagion is developed within the framework. The model is illustrated through an application to contagion between US and European equity markets during the Global Financial Crisis. The results show that correlation contagion dominates coskewness contagion, but that coskewness contagion is significant for Greece. A flight to safety to the US is also evident in the significance of breaks in the skewness parameter in the crisis regime. Comparison to the Asian crisis shows that similar patterns emerge, with a flight to safety to Japan, and Malaysia affected by coskewnes contagion with Hong Kong.
\end{abstract}

Keywords: Financial crisis, contagion, Global Financial Crisis, regime switching, skew-normal distribution, Gibbs sampling, Bayesian model comparison

JEL Classification: C11, C34, G15

\footnotetext{
*Corresponding author is Cody Yu-Ling Hsiao. We would like to thank Kathryn Dominguez, Tom Flavin, Kristin Forbes, Takatoshi Ito, Tokuo Iwaisako, Anella Munro, James Morley, Andrew Rose, Maurice Obstfeld, Tomasz Wozniak, Jun Yu, Vance Martin and the participants at the Society of Nonlinear Dynamics and Econometrics 21st annual symposium, the 24th NBER Annual East Asian Seminar on Economics, the Australasian Meeting of the Econometric Society and the Asian Meeting of the Econometric Society for valuable suggestions. The authors' email addresses are: joshuacc.chan@gmail.com, renee.mckibbin@anu.edu.au, clhsiao@must.edu.mo. Fry-McKibbin acknowledges funding from ARC grant DP120103443. Hsiao acknowledges funding from Macau University of Science and Technology Foundation for Faculty Research Grant FRG-17-019-MSB.
} 


\section{Introduction}

This paper develops a flexible multivariate econometric model of a time-varying joint distribution of asset returns. The useful features of the model are that it allows for regime switching and for the set of assets to follow a joint skew-normal distribution. The model is referred to as a regime switching skew-normal (RSSN) model and is an extension of Hamilton (1989), as the multivariate skew normal distribution assumption allows for non-normality, better reflecting the characteristics of high frequency financial market data. Although the model is suitable for a variety of applications, it is particularly suited to the study of financial market contagion. A feature of the framework is that it is able to estimate the emergence of new linear and non-linear comovements between asset returns that are likely to emerge during a switch to a crisis regime. Since the proposed RSSN model is a high dimensional latent variable model, estimation and inference using the classical approach is difficult. Instead, the model is estimated using Bayesian methods, particularly Markov Chain Monte Carlo (MCMC) algorithms. The model is illustrated through an application to US and European equity markets during the Global Financial Crisis. The majority of papers examining financial market contagion during the recent crisis focus on sovereign debt markets, making the paper complementary to this literature (also see Bekaert et al., 2014).

Table 1 motivates the use of the skew normal-distribution by depicting summary statistics including higher order moments and comoments of the daily equity returns for the US and selected European countries over two periods. ${ }^{1}$ The periods are from 2005 to mid 2007 and from March 2008 to the end of 2014, and are loosely labeled the Great Moderation and the Global Financial Crisis respectively. ${ }^{2}$ The table shows evidence of non-normality in the asset returns of each country in both periods. However, the statistics are very different. In the crisis period, mean returns are lower and negative for all countries compared to those for the Great Moderation. The magnitudes of the minimum, maximum and standard deviation of returns are also larger. Of note are

\footnotetext{
${ }^{1}$ This paper takes a parametric approach and uses the skew normal-distribution to model asset returns. An alternative is to consider a nonparametric approach, such as using the Dirichlet process mixture model (see for examples, Escobar, 1994; Escobar and West, 1995; Chan et al., 2017). The parametric approach is more convenient for our purpose since higher order moments and comoments of the skew normal-distribution are simple functions of the parameters. By contrast, they are more difficult to define under the Dirichlet process mixture model.

${ }^{2}$ Note that the dates are indicative and arbitrarily chosen, loosely corresponding to events signaling the end of the Great Moderation period and the beginning of the Global Financial Crisis period as discussed in Section 5.2.
} 
Table 1:

Preliminary statistics for the equity returns of selected markets in Europe and the US in the Great Moderation and the Global Financial Crisis periods.

\begin{tabular}{|c|c|c|c|c|c|}
\hline & France & Germany & Greece & Italy & US \\
\hline \multicolumn{6}{|c|}{ Great Moderation: January 4, 2005 to July 25, 2007} \\
\hline Mean & 0.065 & 0.107 & 0.090 & 0.043 & 0.038 \\
\hline Minimum & -4.037 & -4.931 & -5.262 & -3.364 & -3.349 \\
\hline Maximum & 3.698 & 4.492 & 5.015 & 3.069 & 2.069 \\
\hline Std. dev. & 0.925 & 1.057 & 01 & 0.875 & 0.634 \\
\hline Skew & -0.234 & -0.564 & -0.371 & -0.279 & -0.333 \\
\hline ation & 0.413 & & 0.178 & 0.384 & \\
\hline Coskewness & -0.113 & -0.157 & -0.151 & -0.151 & \\
\hline \multicolumn{6}{|c|}{ Global Financial Crisis: March 3, 2008 to November 28, 2014} \\
\hline Mean & -0.084 & -0.092 & -0.146 & -0.118 & -0.066 \\
\hline Minimum & -11.737 & -11.326 & -11.366 & -10.864 & -8.201 \\
\hline Maximum & 12.143 & 11.887 & 12.084 & 12.381 & 10.508 \\
\hline Std. dev. & 2.718 & 2.760 & 2.673 & 2.793 & 2.193 \\
\hline Skewness & 0.250 & 0.087 & -0.193 & 0.169 & 0.165 \\
\hline Correlation & 0.533 & 0.520 & 0.350 & 0.485 & \\
\hline Coskewness & -0.098 & -0.116 & -0.189 & -0.132 & \\
\hline
\end{tabular}

Notes: The comoment statistics of correlation and coskewness are calculated for each country with the US. The coskewness statistic is assumed to be symmetric.

the statistics of market comovement for the European returns with those of the US, which show that not only does correlation with the US rise in the Global Financial Crisis period for all European countries, but coskewness becomes more positive. It is natural to expect a significant increase in cross market correlation, or contagion, as is the definition adopted in Forbes and Rigobon (2002). ${ }^{3}$ This is commonly referred to as shift-contagion, emphasizing the change component. However, the change in the coskewness statistics illustrate that the linear correlation coefficient may not reflect all changes in market dependence.

Our definition of contagion extends the concept to include changes in higher order comoments of returns. The RSSN model is able to specifically capture changes in the joint distribution of equity returns occurring through correlation contagion, as well as through coskewness contagion, as is alluded to by the descriptive statistics. ${ }^{4}$ Fry et

\footnotetext{
${ }^{3}$ See King and Wadhwani (1990) for the first application of a correlation based approach to crises in financial markets.

${ }^{4}$ The model could easily be adapted to handle even higher order comoments such as cokurtosis (see Fry-McKibbin and Hsiao, 2018).
} 
al., (2010) examine bivariate coskewness statistics for contagion analogous to those of the Forbes and Rigobon correlation statistic. This work is extended in this paper to a multivariate setting and to a joint testing framework. An additional feature is that the model also captures structural breaks in the moments of the asset returns of the mean, variance and skewness. Disentangling changes in the asset returns distribution due to comoment or to moment changes has implications in determining the appropriate focus of portfolio allocation decisions and international shock mitigation policies, in being domestically oriented, internationally oriented or both. ${ }^{5}$

In addition to the empirical stylized facts relating to the changing nature of higher order comoments during crisis periods, there is a rich theoretical literature on the role of higher order comoments linking asset returns. Often the capital asset pricing model forms the basis of the framework. This includes Harvey and Siddique (2000) where asset pricing models featuring skewness induce coskewness into expected returns. Smith (2007) and Guidolin and Timmerman (2008) show that higher order comoments that are time varying are important for pricing asset returns, while Potì and Wang (2010) show that coskewness risk is a partial explanation for differences in returns on portfolios. Lambert and Hübner (2013) focus on the US market, and find that differences in coskewness across regimes can explain the equity home bias, and that comoment risk is significantly priced by the US market. Such adjustments can occur as risk averse agents alter their skewness and coskewness preferences, as well as their portfolio allocation depending on the regime. Guidolin and Timmerman (2008) and Fry et al., (2010) show that as risk aversion increases, investors prefer positive skewness and positive coskewness. The latter authors provide an explicit expression for risk prices and quantities in terms of higher order comoments. This is consistent with changes in the joint distribution of asset returns such as through contagion and structural breaks. Several papers suggest a role for investor behavior in crisis periods such as herd behavior, wake up calls, sudden stops, wealth effects, portfolio rebalancing, credit contractions, self fulfilling expectations and information asymmetry. See the classic articles by Krugman (1998), Kaminsky and Schmukler (1999), Calvo and Mendoza (2000), Kyle and Xiong (2001), Loisel and Martin (2001) and Yuan (2005). These models are not mutually exclusive to those based on higher order comoments, and all are consistent with the increasing risk aversion of investors inherent in crisis periods.

\footnotetext{
${ }^{5}$ Fry-McKibbin et al., (2014) show that mispricing of asset returns can undermine hedging strategies if risk reflected in higher order moments is ignored during crisis episodes.
} 
There is some evidence of a flight to safety, liquidity or quality during crisis periods. Baur and Lucey (2009), Baele et al., (2013) and Adrian et al., (2015) examine flights between stocks and bonds. During the European sovereign debt crisis, Allegret et al., (2017) find that the US banking sector may have benefitted, while Ehrmann and Fratscher (2017) find evidence of a flight to quality in Europe in bond markets. We examine the concept of flight to safety in equity markets across countries in terms of the moments and comoments across the regimes. As Adrian et al., (2015) show, there are possibly non-linearities in the flight to safety relationship, in their case between stocks and bonds.

An appealing feature of the RSSN model is that the switching between regimes is endogenous. Crisis duration is usually the choice of the researcher and exogenously imposed on the model (see Gravelle et al., 2006 for an exception). Figure 1 illustrates the potential arbitrariness of the crisis dating choice and how this could lead to malleable conclusions. The figure shows rolling bivariate test statistics of contagion based on changes in correlation between the US and each of the European equity returns shown in Table 1. A value of the test statistic above the critical value line is evidence of contagion in the previous 30 days compared to the non-crisis period. The figure shows that contagion is not significant on every crisis day, particularly for Greece, and also highlights that the test results depend on the crisis dating. The RSSN model circumvents these problems as it embeds the flexibility to switch between crisis and non-crisis days. Further, crisis days are not necessarily consecutive in time.

Dungey et al., (2015) specify an alternative approach to endogenously model crisis periods using smooth transition functions in conjunction with a GARCH model, while others such as Contessi et al., (2014) and Guidolin and Tam (2013) use break point tests. Ang and Bekaert (2002), Billio and Caporin (2005), Gravelle et al., (2006), Pelletier (2006), Kim et al., (2008), Guo et al., (2011) and Kasch and Caporin (2013) use regime switching models to test for market dependence, but most of these assume a normally distributed error term. Few papers specify a regime switching model with higher order moments. Harvey and Siddique (2000), Ang and Timmermann (2011) and Grothe et al., (2014) are examples, but they do not focus on contagion. However, the label of contagion adopted in this paper could equally apply.

The empirical results show that several patterns emerge. The transition to a crisis period is volatile in terms of switching between the non-crisis and crisis regimes. Equity markets show evidence of a shift towards a crisis state before the key trigger of the 

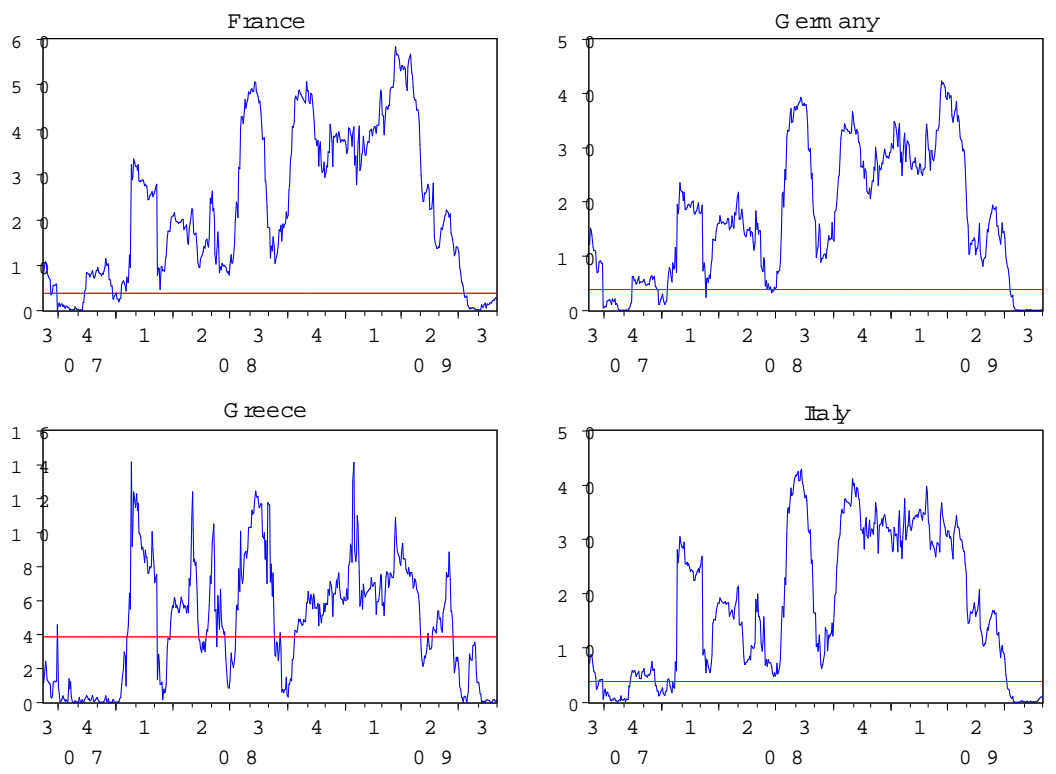

Figure 1: Bivariate test statistics of contagion based on changes in correlation between the equity returns of selected markets in Europe and the US. The statistics are calculated with respect to a fixed non-crisis period from January 5, 2005 to July 25, 2007. The crisis period is a 30 day rolling window from July 26, 2008 to August 31, 2009. The horizontal line represents the $\chi_{1}^{2}$ critical value of 3.84. The data is prefiltered using a $\operatorname{VAR}(5)$. 
collapse of Bear Stearns in March 2008. When in a crisis regime, contagion through traditional correlation dominates coskewness contagion, with correlation contagion being significant for all of the asset returns of the European countries in the sample when paired with the US. Coskewness contagion is significant only for the Greece-US pair, confirming the use of the correlation coefficient as a first measure of contagion. In comparison with the Asian Financial Crisis between Hong Kong and several Asian countries similar qualitative results emerge. There is volatility in the regime while transitioning from the non-crisis to the crisis period. Correlation based contagion is significant for all countries with Hong Kong. Coskewness contagion is significant for the one case of the Malaysia-Hong Kong pair. Greece and Malaysia have abrupt changes to policies affecting international investors in common, with Greece defaulting on their sovereign debt, and Malaysia responding to the crisis through the imposition of capital controls. The results also validate the importance of considering contagion and structural breaks in a multivariate setting as evident by their joint significance.

In both crises there is a clear flight to safety in the moment break tests. The US in the Global Financial Crisis and Japan in the Asian Financial Crisis are the only asset markets showing breaks in all three moments of the mean, variance and skewness. The skewness coefficient in particular is the most relevant for risk averse investors. In both models, the skewness coefficients of all markets become more positive, as is consistent with the needs of risk averse investors. The exception is for skewness in the US which becomes more negative, indicating investors lower risk aversion in the US market, and greater risk appetite for US assets relative to those in Europe. This is despite the US being a source of shocks during the crisis period.

The rest of the paper is organized as follows. Section 2 presents the multivariate RSSN model of asset returns. Section 3 documents the Bayesian estimation approach including the Markov Chain Monte Carlo (MCMC) sampling scheme. Section 4 outlines the hypotheses and testing methods for the contagion and structural break tests. Section 5 presents the empirical analysis for the Global Financial Crisis including a comparison to the Asian Financial Crisis. Section 6 concludes.

\section{An RSSN Model of Asset Returns}

An RSSN model is specified in this section to provide a general framework to analyze linear and non-linear contagion between asset markets and structural breaks in the 
moments of asset markets across regimes. Section 2.1 sets out the details of the multivariate skew-normal distribution that underlies the regime switching model described in Section 2.2. The skew-normal assumption combined with the regime switching allows the correlation and coskewness contagion parameters in a crisis regime to change. In comparison to other models of contagion, there is also an allowance for structural breaks in asset moments that have no associated transmission to other asset markets such as in the mean, variance and skewness.

\subsection{Skew-normal Distribution}

The skew-normal distribution as developed by Sahu et al., (2003) has the following latent variable representation

$$
\begin{aligned}
y_{t} & =\mu+\Omega Z_{t}+\varepsilon_{t}, \\
\varepsilon_{t} & \stackrel{i i d}{\sim} N(0, \Sigma), \\
Z_{t} & \stackrel{i i d}{\sim} N\left(c 1_{m}, I_{m}\right) 1\left(Z_{j t}>c, j=1, \ldots, m\right),
\end{aligned}
$$

where $y_{t}=\left(y_{1 t}, \ldots, y_{m t}\right)^{\prime}$ is an $m$-dimensional random vector with $t=1, \ldots, T, \mu$ is an $m \times 1$ vector of constants, $\Omega$ is an $m \times m$ skewness coskewness matrix, $Z_{t}=$ $\left(Z_{1 t}, \ldots, Z_{m t}\right)^{\prime}$ is an $m$-dimensional random vector, $\varepsilon_{t}$ is an $m \times 1$ innovation vector, $\Sigma$ is an $m \times m$ variance covariance matrix, $1_{m}$ is an $m \times 1$ column of ones, $I_{m}$ is the identity matrix, and $1(\cdot)$ is a (scalar) indicator function which takes a value of 1 if all $Z_{j t}$ are greater than $c$ and 0 otherwise. ${ }^{6}$

The inclusion of the vector of latent variables $Z_{t}$ allows for skewness in the distribution which enriches the dependence between the components of $y_{t}$. Sahu et al., (2003) assume that $\Omega$ is a diagonal skewness-coskewness matrix. However, this assumption is restrictive in the context of modeling comovements since it does not allow for coskewness between the components of $y_{t}$. Coskewness for $y_{t}$ is introduced by relaxing the assumption that $\Omega$ is diagonal. Specifically, $\Omega=\left(\omega_{i j}\right)$ is a full $m \times m$ coskewness matrix with $i, j=1, \ldots, m$. The off-diagonal elements of $\Omega$ are the coskewness parameters which control asymmetric dependence between the components of $y_{t}{ }^{7}$

\footnotetext{
${ }^{6}$ The constant term $c$ is set to be $-\sqrt{2 / \pi}$, so that the latent variables $Z_{t}$ do not affect the unconditional expectation of $y_{t}$.

${ }^{7}$ An alternative identification strategy is to assume that $\Omega$ is triangular. Here, we assume that $\Omega$ is symmetric. Since the two assumptions leave the same number of free parameters in $\Omega$, both solutions are essentially the same. The latter restriction is chosen as it gives an easier interpretation of the parameters.
} 
The probability density function of $y_{t}$ marginally of $Z_{t}$ is

$$
f_{S N}\left(y_{t} ; \mu, \Sigma, \Omega\right)=\frac{2^{m}}{\operatorname{det}\left(\Sigma+\Omega^{2}\right)^{1 / 2}} f_{N}\left(\left(\Sigma+\Omega^{2}\right)^{-\frac{1}{2}}\left(y_{t}-\mu\right)\right) \operatorname{Pr}(V>0),
$$

where

$$
V \sim N\left(\Omega\left(\Sigma+\Omega^{2}\right)^{-1}\left(y_{t}-\mu\right), I_{m}-\Omega\left(\Sigma+\Omega^{2}\right)^{-1} \Omega\right) .
$$

$f_{N}\left(y_{t}\right)$ is the density function of the standard multivariate normal distribution with mean 0 and identity covariance matrix $I_{m}$ evaluated at $y_{t}$. If $\Omega=0$, then the skewnormal distribution in equations (1) to (3) reduces to the usual multivariate normal specification with the density given by

$$
f_{N}\left(y_{t} ; \mu, \Sigma\right)=\frac{1}{\operatorname{det}(\Sigma)^{1 / 2}} f_{N}\left(\Sigma^{-\frac{1}{2}}\left(y_{t}-\mu\right)\right) .
$$

Figure 2 plots the contours of the bivariate skew-normal density in equation (4) with zero mean $(\mu=0)$, identity scale matrix $\left(\Sigma=I_{2}\right)$ and various patterns of asymmetric dependence $\left(\Omega=\left(\omega_{i j}\right), i, j=1,2\right)$. The center panel of Figure 2 illustrates the case of a symmetric bivariate normal distribution with $\omega_{11}=\omega_{22}=\omega_{12}=\omega_{21}=0$. The offcentre panels of the figure emphasize the skewness and heavy tails generated compared to the bivariate distribution in the centre panel as skewness and coskewness of the distribution interact as the parameters $\omega_{i j}$ change. These plots reflect the relationships in high frequency financial market data across the varying regimes as illustrated in Table 1.

\subsection{Regime Switching with the Skew-normal Distribution}

The RSSN model of asset returns extends the regime switching model of Hamilton (1989) by assuming that under each regime, $y_{t}$ has a multivariate skew-normal distribution. This extension is useful as it not only captures the stylized behavior of asset returns including asymmetry, heavy tails, heteroskedasticity, time-varying linear and non-linear comoments among the asset markets, but also controls parameters which are allowed to differ across the states.

Consider the multivariate skew-normal distribution of a set of asset returns $y_{t}$ of Section 2.1, but allow for the model parameters to be state dependent as follows

$$
\begin{aligned}
y_{t} & =\mu_{s_{t}}+\Omega_{s_{t}} Z_{t}+\varepsilon_{t}, \\
\varepsilon_{t} & \stackrel{i i d}{\sim} N\left(0, \Sigma_{s_{t}}\right), \\
Z_{t} & \stackrel{\text { iid }}{\sim} N\left(c 1_{m}, I_{m}\right) 1\left(Z_{j t}>c, j=1, \ldots, m\right) .
\end{aligned}
$$



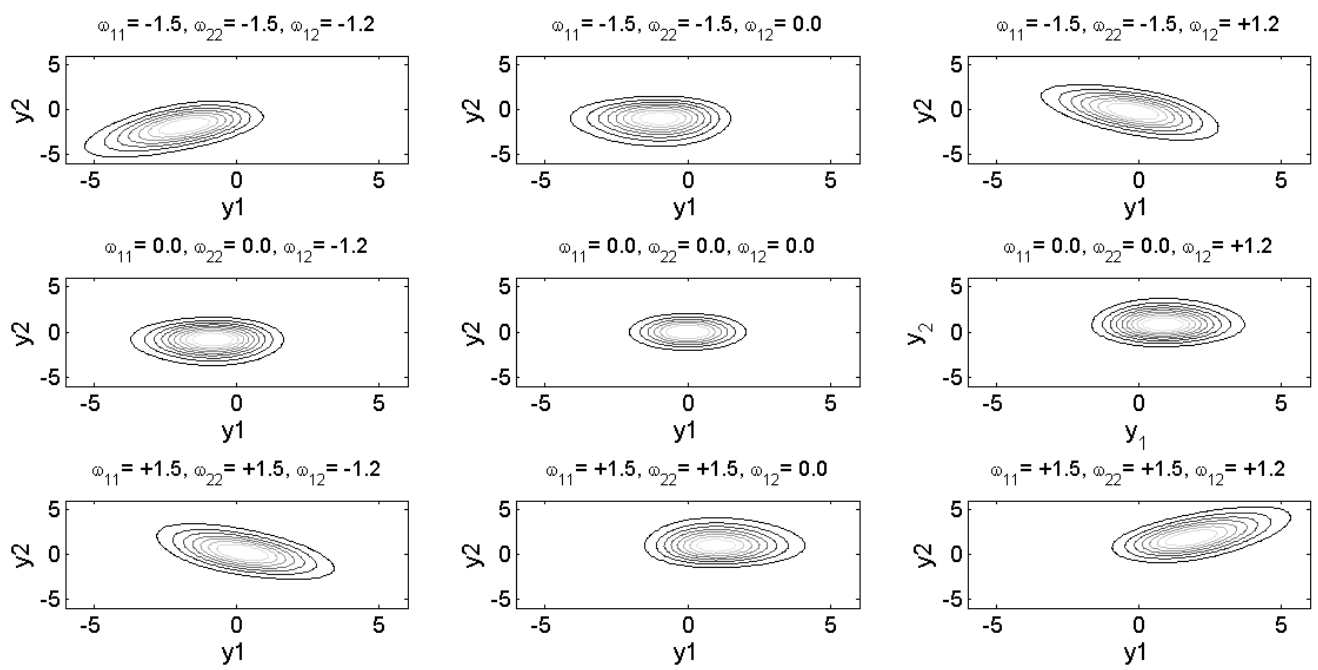

Figure 2: Contour plots of the bivariate skew-normal density. The plots are of equation (4) with zero mean $(\mu=0)$, identity scale matrix $\left(\Sigma=I_{2}\right)$ and differing values of coskewness $\omega_{i j}$. The central panel corresponds to a symmetric bivariate normal distribution with $\omega_{11}=\omega_{22}=\omega_{12}=\omega_{21}=0$.

The regime $s_{t}$ at time $t$ is a binary variable that takes the values of 0 or 1 , or $s_{t} \in\{0,1\}$. There are two sets of regime-dependent parameters, $\left(\mu_{0}, \Omega_{0}, \Sigma_{0}\right)$ and $\left(\mu_{1}, \Omega_{1}, \Sigma_{1}\right)$. To emphasize the regime, the set of parameters $\left(\mu_{l}, \Omega_{l}, \Sigma_{l}\right)$ is sometimes written as $\left(\mu_{s_{t}=l}, \Omega_{s_{t}=l}, \Sigma_{s_{t}=l}\right)$ for $l=0,1$.

The flexibility of the RSSN model allows the parameters including the means, $\mu_{s_{t}}$, coskewness, $\Omega_{s_{t}}$, and the error cross-covariances, $\Sigma_{s_{t}}$ in equations (7) to (9) to change in regime $s_{t}=1$ compared to regime $s_{t}=0$. Changes in the parameters controlling market linkages of correlation and coskewness during the second regime are contagion. Changes in the moment parameters of the mean, variance and skewness in the second regime are structural breaks.

For estimation purposes, equations (7) to (9) are rewritten as

$$
\begin{aligned}
& y_{t}=X_{t} \beta_{s_{t}}+\varepsilon_{t}, \\
& \varepsilon_{t} \stackrel{i i d}{\sim} N\left(0, \Sigma_{s_{t}}\right),
\end{aligned}
$$

where

$$
X_{t}=\left(I_{m}, I_{m} \otimes Z_{t}^{\prime}\right), \quad \beta_{s_{t}}=\left(\mu_{s_{t}}^{\prime}, \omega_{s_{t}}^{\prime}\right)^{\prime}, \quad \omega_{s_{t}}=\operatorname{vec}\left(\Omega_{s_{t}}^{\prime}\right) .
$$

The dimensions of $\mu_{s_{t}}, \omega_{s_{t}}$ and $\beta_{s_{t}}$ are $m, k$ and $(m+k)$ respectively with $k=m^{2}$. 
To complete the model, the process governing the underlying state of the regime, $s_{t}$, needs to be specified. Assume the standard Markov transition

$$
\operatorname{Pr}\left(s_{t}=1 \mid s_{t-1}=i\right)=p_{i t},
$$

for $i=0$ and 1 , where the probabilities $p_{i t}$ are fixed constants that vary with time. The parameters of the RSSN model are

$$
\Theta=\left(\beta_{0}, \beta_{1}, \Sigma_{0}, \Sigma_{1}\right)
$$

For later reference, stack $y=\left(y_{1}^{\prime}, \ldots, y_{T}^{\prime}\right)^{\prime}, Z=\left(Z_{1}^{\prime}, \ldots, Z_{T}^{\prime}\right)^{\prime}$ and $s=\left(s_{1}, \ldots, s_{T}\right)^{\prime}$. For convenience, let $\mu_{i, l}$ denote the $i$-th element of $\mu_{l}, l=0,1$, and similarly define $\Sigma_{i j, l}$ and $\Omega_{i j, l}$.

Notably, the correlation coefficient $\rho_{i j, s_{t}}$ can also be estimated and is

$$
\rho_{i j, s_{t}}=\frac{\Sigma_{i j, s_{t}}}{\sqrt{\sum_{i i, s_{t}}} \sqrt{\sum_{j j, s_{t}}}}, s_{t}=0,1 .
$$

For convenience, $\rho_{i j, s_{t}}$ is sometimes labeled as $\rho_{i j, l}$ with $l=0,1$.

\section{Bayesian Estimation of the RSSN Model}

A Bayesian approach is used to estimate the model parameters. ${ }^{8}$ MCMC methods are used to obtain draws from the posterior distribution required for the analysis as documented in this Section.

Likelihood Function and Priors The complete-data likelihood function of the RSSN model in equations (10) to (11) is given by

$$
f(y \mid Z, \Theta, s)=(2 \pi)^{-\frac{m T}{2}} \prod_{t=1}^{T}\left|\Sigma_{s_{t}}\right|^{-\frac{1}{2}} \exp \left\{-\frac{1}{2} \sum_{t=1}^{T}\left[y_{t}-X_{t} \beta_{s_{t}}\right]^{\prime} \Sigma_{s_{t}}^{-1}\left[y_{t}-X_{t} \beta_{s_{t}}\right]\right\}
$$

where $\Theta=\left(\beta_{0}, \beta_{1}, \Sigma_{0}, \Sigma_{1}\right)$ and $s_{t} \in\{0,1\}$.

The priors for the model parameters are specified as

$$
\begin{aligned}
\beta_{s_{t}} & \sim N\left(\underline{\beta}, \underline{V}_{\beta}\right), \\
\Sigma_{s_{t}} & \sim I W\left(\underline{\tau}_{\Sigma}, \underline{S}_{\Sigma}\right), \\
\operatorname{Pr}\left(s_{t}=1 \mid s_{t-1}=i\right) & =p_{i t}, \quad \operatorname{Pr}\left(s_{t}=0 \mid s_{t-1}=i\right)=1-p_{i t},
\end{aligned}
$$

\footnotetext{
${ }^{8}$ The model was estimated using MATLAB. The code is available at http://joshuachan.org/code.html.
} 
where $I W\left(\underline{\tau}_{\Sigma}, \underline{S}_{\Sigma}\right)$ denotes the inverse-Wishart distribution with degree of freedom $\underline{\tau}_{\Sigma}$ and scale matrix $\underline{S}_{\Sigma}$. The prior mean for $\beta_{s t}$ is set to $\underline{\beta}=\left(\underline{\mu}^{\prime}, \underline{\omega}^{\prime}\right)^{\prime}$, and the prior covariance matrix for $\beta_{s_{t}}$ is set to $\underline{V}_{\beta}=\left[\begin{array}{cc}\phi_{\mu} I_{m} & 0 \\ 0 & \phi_{\omega} I_{k}\end{array}\right]$, where $k=m^{2}$.

Posterior Analysis The Gibbs sampler is used for estimating the RSSN model. It follows from Bayes rule that the joint posterior distribution is proportional to the product of the complete-data likelihood function and the joint prior density, as follows

$$
\pi(\Theta, Z, s \mid y) \propto f(y \mid Z, \Theta, s) f(Z) f(s \mid \Theta) \pi(\Theta)
$$

where $f(Z)$ and $f(s \mid \Theta)$ are given in equations (9) and (18) respectively. Note that the notation $\pi$ denotes the prior and posterior density functions. The likelihood function $f(y \mid Z, \Theta, s)$ is given in equation (15). By assuming prior independence between $\beta$ and $\Sigma$, the joint prior density is given by

$$
\pi(\Theta)=\pi\left(\beta_{0}\right) \pi\left(\beta_{1}\right) \pi\left(\Sigma_{0}\right) \pi\left(\Sigma_{1}\right)
$$

Posterior draws from the joint posterior distribution can be obtained via the following Gibbs sampler:

- Step 1: Specify starting values for $\Theta^{(0)}=\left(\beta_{0}^{(0)}, \beta_{1}^{(0)}, \Sigma_{0}^{(0)}, \Sigma_{1}^{(0)}\right)$ and $Z^{(0)}$, where $\beta_{l}^{(0)}=\left(\mu_{l}^{(0)^{\prime}}, \omega_{l}^{(0)^{\prime}}\right)^{\prime}$ with $l=0,1$. Set counter loop $=1, \ldots n$.

- Step 2: Generate $s^{(l o o p)}$ from $\pi\left(s \mid y, Z^{(l o o p-1)}, \Theta^{(l o o p-1)}\right)$ where $\Theta^{(l o o p)}=\left(\beta^{(l o o p)}, \Sigma^{(l o o p)}\right)$.

- Step 3: Generate $\beta_{l}^{(l o o p)}$ from $\pi\left(\beta_{l} \mid y, Z^{(l o o p-1)}, \Sigma_{l}^{(l o o p-1)}, s^{(l o o p)}\right)$.

- Step 4: Generate $\Sigma_{l}^{(l o o p)}$ from $\pi\left(\Sigma_{l} \mid y, Z^{(l o o p-1)}, \beta_{l}^{(l o o p)}, s^{(l o o p)}\right)$.

- Step 5: Generate $Z^{(l o o p)}$ from $\pi\left(Z \mid y, \Theta^{(l o o p)}, s^{(l o o p)}\right)$.

- Step 6: Set loop $=l o o p+1$ and go to Step 2 .

The number of iterations set for Steps 2 to 5 is $n$. The first $n_{0}$ of these are discarded as burn-in draws, and the remaining $n_{1}$ are retained to compute the parameter estimates, where $n=n_{0}+n_{1}$. The full conditional distributions are given below, and their derivations are presented in Appendix A. 
The posterior distribution for $\beta_{l}, l=0,1$, conditional on $y, Z, \Sigma_{0}, \Sigma_{1}$ and $s$ is a $q$-variate normal distribution with $q=m+k$ given by

$$
\left(\beta_{l} \mid y, Z, \Sigma_{l}, s\right) \sim N_{q}\left(\widehat{\beta}_{l}, D_{\beta_{l}}\right), l=0,1,
$$

where $D_{\beta_{l}}=\left(\underline{V}_{\beta}^{-1}+\sum_{t=1}^{T} 1\left(s_{t}=l\right) X_{t}^{\prime} \Sigma_{s_{t}}^{-1} X_{t}\right)^{-1}$ and $\widehat{\beta}_{l}=D_{\beta_{l}}\left[\underline{V}_{\beta}^{-1} \underline{\beta}+\sum_{t=1}^{T} 1\left(s_{t}=l\right) X_{t}^{\prime} \Sigma_{s t}^{-1} y_{t}\right]$.

The posterior distribution for $\Sigma_{l}, l=0,1$, conditional on $y, Z, \beta_{0}, \beta_{1}$ and $s$ has an inverse-Wishart distribution

$$
\left(\Sigma_{l} \mid y, Z, \beta_{l}, s\right) \sim I W\left(\tau_{\Sigma_{l}}, S_{\Sigma_{l}}\right)
$$

where $\tau_{\Sigma_{l}}=\underline{\tau}_{\Sigma}+\sum_{t=1}^{T} 1\left(s_{t}=l\right)$ and $S_{\Sigma_{l}}=\underline{S}_{\Sigma}+\sum_{t=1}^{T} 1\left(s_{t}=l\right)\left(y_{t}-X_{t} \beta_{s_{t}}\right)\left(y_{t}-X_{t} \beta_{s_{t}}\right)^{\prime}$.

Next, the latent variables $Z_{1}, \ldots, Z_{T}$ are conditionally independent given $y, \beta_{0}, \beta_{1}, \Sigma_{0}, \Sigma_{1}$

and $s$. In fact, each $Z_{t}$ has an independent truncated multivariate normal distribution

$$
\left(Z_{t} \mid y, \Theta, s\right) \stackrel{i n d}{\sim} N\left(\widehat{Z}_{t}, D_{Z_{t}}\right) 1\left(Z_{j t}>c, j=1, \ldots, m\right)
$$

where $D_{Z_{t}}=\left(I_{m}+\delta_{s_{t}}^{\prime} \Sigma_{s_{t}}^{-1} \delta_{s_{t}}\right)^{-1}$ and $\widehat{Z}_{t}=D_{Z_{t}}\left(c 1_{m}+\delta_{s_{t}}^{\prime} \Sigma_{s_{t}}^{-1}\left(y_{t}-\mu_{s_{t}}\right)\right)$. A feasible sampling approach to obtain the draws from the above truncated multivariate normal distribution is to draw $Z_{t}$ component by component, where each component follows a truncated univariate normal distribution where all other components are given (Geweke, 1991 and Robert, 1995). Draws from the truncated univariate normal distribution are generated by using the inverse transform method (Kroese et al., 2011, p.45).

To generate the regime variable $s_{t}$, a multi-move Gibbs sampling method is used. In particular, the success probabilities are computed using standard filtering and smoothing algorithms for hidden Markov models, such as the algorithms described in Chib (1996) and Frühwirth-Schnatter (2006).

\section{Testing for Contagion and Structural Breaks}

This section sets out the procedure for testing for contagion and structural breaks. For reference, the restrictions on the RSSN model parameters for the tests for contagion and structural breaks and the method used to evaluate each hypothesis are summarized in Table 2. Details describing the methods used to evaluate the hypotheses are contained in Section 4.1, while Sections 4.2 to 4.4 outline the hypothesis tests. 
Table 2:

Summary of the restrictions on the model parameters and the hypothesis evaluation methods for the tests for contagion and structural breaks.

\begin{tabular}{|c|c|c|c|}
\hline \multirow[b]{2}{*}{ Tests } & \multirow{2}{*}{$\begin{array}{r}\text { Method } \\
\text { (DR) }\end{array}$} & \multicolumn{2}{|c|}{ Restrictions } \\
\hline & & market $i$ & $\forall i$ \\
\hline \multicolumn{4}{|c|}{ Contagion tests $(i \neq j)$} \\
\hline Correlation & $p$ & $\rho_{i j, 0}<\rho_{i j, 1}$ & $\Upsilon_{0}<\Upsilon_{1}$ \\
\hline Coskewness & $B F$ & $\omega_{i j, 0}=\omega_{i j, 1}$ & $\Omega_{0}=\Omega_{1}$ \\
\hline $\begin{array}{l}\text { Corr. } \\
\text { \&coskew. }\end{array}$ & $B F$ & $\rho_{i j, 0}=\rho_{i j, 1}, \omega_{i j, 0}=\omega_{i j, 1}$ & $\Upsilon_{0}=\Upsilon_{1}, \Omega_{0}=\Omega_{1}$ \\
\hline \multicolumn{4}{|c|}{ Structural break tests $(i)$} \\
\hline Mean & $p$ & $\mu_{i, 0}>\mu_{i, 1}$ & $\mu_{0}>\mu_{1}$ \\
\hline Variance & $p$ & $\Sigma_{i i, 0}<\Sigma_{i i, 1}$ & $\Sigma_{0}<\Sigma_{1}$ \\
\hline Skewness & $B F$ & $\omega_{i i, 0}=\omega_{i i, 1}$ & $\omega_{0}=\omega_{1}$ \\
\hline $\begin{array}{l}\text { Mean,var. } \\
\text { \&skew. }\end{array}$ & $B F$ & $\mu_{i, 0}=\mu_{i, 1}, \Sigma_{i i, 0}=\Sigma_{i i, 1}, \omega_{i i, 0}=\omega_{i i, 1}$ & $\mu_{0}=\mu_{1}, \Sigma_{0}=\Sigma_{1}, \omega_{0}=\omega_{1}$ \\
\hline \multicolumn{4}{|c|}{ Joint contagion $(i \neq j)$ and structural break tests $(i)$} \\
\hline All & $B F$ & $\begin{array}{c}\mu_{i, 0}=\mu_{i, 1}, \Sigma_{i i, 0}=\Sigma_{i i, 1}, \omega_{i i, 0}=\omega_{i i, 1} \\
\& \rho_{i j, 0}=\rho_{i j, 1}, \omega_{i j, 0}=\omega_{i j, 1}\end{array}$ & $\begin{array}{c}\mu_{0}=\mu_{1}, \Sigma_{0}=\Sigma_{1}, \omega_{0}=\omega_{1}, \\
\Upsilon_{0}=\Upsilon_{1}, \Omega_{0}=\Omega_{1}\end{array}$ \\
\hline
\end{tabular}

Notes: The tests are for a change in each parameter in the crisis period $s_{t}=1$ compared to a non-crisis period $s_{t}=0$. The method of hypothesis evaluation (DR) for each test is indicated in the table. $p$ denotes that a decision is probability based. $B F$ denotes that a decision is based on the log of the Bayes factor using the model selection evidence categories in Table 3. 
The RSSN model is the unrestricted model $\left(M_{u}\right)$ with two sets of regime-specific parameters. These are the regime-specific mean vectors $\mu_{0}$ and $\mu_{1}$ (each of dimension $m \times 1$ ), covariance matrices $\Sigma_{0}$ and $\Sigma_{1}$ (each of dimension $\left.m \times m\right)$ and coskewness matrices $\Omega_{0}$ and $\Omega_{1}$ (each of dimension $m \times m$ ). Recall that $\mu_{i, l}$ denotes the $i$-th element of $\mu_{l}$, and similarly, for $\Sigma_{i j, l}$ and $\Omega_{i j, l}$. Notably, the correlation coefficient $\rho_{i j, l}$ is estimated by the covariance $\left(\Sigma_{i j, l}\right)$ divided by the product of the square root of the variances $\Sigma_{i i, l}$ and $\Sigma_{j j, l}$. For later reference $\Upsilon_{l}$ denotes the sum of the individual correlation coefficients $\Upsilon_{l}=\sum_{i=1}^{m} \sum_{j \neq i}^{m} \rho_{i j, l}$ used in the joint tests for correlation contagion.

\subsection{Hypothesis Test Evaluation Methods}

Two decision rules (DR) are available for evaluating the hypotheses depending upon the form that the hypothesis for contagion or structural breaks takes.

Hypotheses with inequality restrictions If the hypothesis contains an inequality restriction then the probability of contagion or a structural break is simply calculated using the proportion that the hypothesis is true in the MCMC draws and is denoted by $p$.

Hypotheses with equality restrictions If the tests involve equality restrictions, Bayesian model comparison methods using the natural logarithm of the Bayes factor are conducted, and is denoted by $B F$. Bayesian model comparison provides a unified approach for comparing non-nested models, and is an alternative to classical hypothesis testing. Consider comparing models $M_{r}$ and $M_{u}$. Evidence in favor of model $M_{r}$ can be measured by the Bayes factor, defined as

$$
B F_{r u}=\frac{p\left(y \mid M_{r}\right)}{p\left(y \mid M_{u}\right)}
$$

where $p\left(y \mid M_{r}\right)$ and $p\left(y \mid M_{u}\right)$ are the marginal likelihoods of the data under models $M_{r}$ and $M_{u}$ respectively. Intuitively, the marginal likelihood $p\left(y \mid M_{r}\right)$ is simply the marginal distribution of $y$ under model $M_{r}$ evaluated using the data. If the data are improbable under model $M_{r}$, the marginal likelihood will be small and vice versa. Hence, the Bayes factor $B F_{r u}$, which is the ratio of the marginal likelihoods of the two models shows which model better predicts the data. The marginal likelihood of the data under model $i$ can be defined as

$$
p\left(y \mid M_{i}\right)=\frac{f(y \mid \Theta) \pi(\Theta)}{\pi(\Theta \mid y)}, \quad i=r, u
$$


Table 3:

Model selection evidence categories for the log of the Bayes factor.

\begin{tabular}{ll}
\hline \hline Value of $\ln \left(B F_{r u}\right)$ & Evidence categories \\
\hline$(0, \infty)$ & Evidence in support of model $M_{r}$ \\
$(-1.15,0)$ & Very slight evidence in support of model $M_{u}$ \\
$(-2.30,-1.15)$ & Slight evidence in support of model $M_{u}$ \\
$(-4.60,-2.30)$ & Strong evidence in support of model $M_{u}$ \\
$(-\infty,-4.60)$ & Decisive evidence in support of model $M_{u}$ \\
\hline \multicolumn{2}{l}{ Notes: The log of the Bayes factor (ln $\left(B F_{r u}\right)=\ln \left(p\left(y \mid M_{r}\right)\right)-\ln \left(p\left(y \mid M_{u}\right)\right)$} \\
is used for model selection following Jeffrey's rule (Jeffreys, 1961).
\end{tabular}

where $\Theta$ is a parameter set in the model, $f(y \mid \Theta)$ is a likelihood and $\pi(\Theta \mid y)$ is a posterior density. The prior density can easily be evaluated, whereas the evaluation of the likelihood and the posterior density requires Monte Carlo simulation methods. Chib's method is used to compute the marginal likelihoods when required (Chib, 1995; Chib and Jeliazkov, 2001).

The posterior odds ratio for model $M_{r}$ against model $M_{u}$ is related to their Bayes factor which is as follows

$$
P O_{r u}=\frac{\pi\left(M_{r}\right)}{\pi\left(M_{u}\right)} B F_{r u}
$$

where $\pi\left(M_{r}\right)$ and $\pi\left(M_{u}\right)$ are the prior probabilities of models $M_{r}$ and $M_{u}$. Clearly, if both models have an equally likely prior, then the Bayes factor is also the posterior odds ratio of the two models. If the two models under comparison are nested, then the Bayes factor can be calculated using the Savage-Dickey density ratio which is often much simpler to compute (Verdinelli and Wasserman, 1995). Since hypothesis testing can be framed as comparing nested models, the density ratio can be used to compute the relevant Bayes factor. The details of the Savage-Dickey density ratio are contained in Appendix B. ${ }^{9}$

Model $M_{r}$ is chosen over model $M_{u}$ if the Bayes factor in favor of $M_{r}\left(B F_{r u}\right)$ is sufficiently large. The choice of threshold on which this decision is made is based on the scale of evidence for model selection as proposed by Jeffreys (1961), shown in Table 3.

\footnotetext{
${ }^{9}$ This approach can only be utilized when the two models are nested, so that there exists at least one point in the parameter space of the unrestricted model where its likelihood is equivalent to that of the restricted model.
} 


\subsection{Contagion}

The first type of test for contagion between markets is based on an increase in the correlation coefficient in $s_{t}=1$ compared to $s_{t}=0$ (Forbes and Rigobon, 2002). That is,

$$
\rho_{i j, s_{t}=1}>\rho_{i j, s_{t}=0}, i \neq j .
$$

The prior is that the correlation parameters are expected to rise as markets move together more closely during a crisis. The relevant form of the correlation change test between asset markets $i$ and $j$ is $\rho_{i j, 1}-\rho_{i j, 0}>0$. The probability of correlation contagion between markets $i$ and $j$ is

$$
\operatorname{Pr}\left(\rho_{i j, 1}-\rho_{i j, 0}>0 \mid y, M_{u}\right)
$$

which can be calculated from the MCMC draws.

The test for joint correlation contagion between the $m-1$ pairs of asset returns with market $j$ is also considered. The relevant restriction for testing for joint correlation contagion is $\Upsilon_{0} \leq \Upsilon_{1}$ where $\Upsilon_{l}$ is the sum of the individual correlation coefficients $\Upsilon_{l}=\sum_{i=1}^{m} \sum_{j \neq i}^{m} \rho_{i j, l}$. As before, the joint probability of correlation contagion across the $m-1$ markets with market $j$ can be calculated from the MCMC draws.

The coskewness contagion test is given by

$$
\omega_{i j, s_{t=0}} \neq \omega_{i j, s_{t=1}}, i \neq j
$$

The test is for a change in the asymmetric dependence of returns $i$ and $j$ in regime $s_{t}=0$ compared with regime $s_{t}=1$. The restricted model for the coskewness change test is $\omega_{i j, 0}=\omega_{i j, 1}, i \neq j$. This hypothesis is compatible with the bivariate coskewness statistics for contagion of Fry et al., (2010). The joint test for contagion through shifts in coskewness across all $m$ asset markets is an extension of that paper with the restriction on the model $\sum_{i=1}^{m} \sum_{j \neq i}^{m} \omega_{i j, 0}=\omega_{i j, 1}$, alternatively expressed as $\omega_{0}=\omega_{1}$. The relevant Bayes factors are computed using the marginal likelihoods.

\subsection{Structural Breaks}

The hypothesis for a structural break in the mean for asset market $i$ during $s_{t}=1$ compared to $s_{t}=0$ is based on a reduction in the mean as in financial crisis periods it is expected that returns are lower. The probability for market $i$ is

$$
\operatorname{Pr}\left(\mu_{i, 1}-\mu_{i, 0}<0 \mid y, M_{u}\right)
$$


and is calculated from the MCMC draws.

A joint version of a test for a structural break in the mean across all $m$ asset markets is also considered. While the test for a structural break in an individual market uses the elements specific to market $i\left(\mu_{i, 0}\right.$ and $\left.\mu_{i, 1}\right)$, the joint test for a mean break for all $m$ markets utilizes the whole mean vectors $\mu_{1}$ and $\mu_{0}$ in the computation. The relevant probability has the form

$$
\operatorname{Pr}\left(\sum_{i=1}^{m} \mu_{i, 0}-\mu_{i, 1} \geq 0 \mid y, M_{u}\right),
$$

which is calculated from the MCMC draws.

The second type of test for a structural break is a for a change in the variance of the returns of market $i$ in the crisis period compared with the non-crisis period,

$$
\Sigma_{i i, s_{t}=1} \neq \Sigma_{i i, s_{t}=0}
$$

This test for a structural break in the variance has the form $\Sigma_{i i, 1}-\Sigma_{i i, 0}>0$ as in the financial crisis regime it is expected that the variance of returns will increase. The probability is

$$
\operatorname{Pr}\left(\Sigma_{i i, 1}-\Sigma_{i i, 0}>0 \mid y, M_{u}\right) .
$$

This is calculated from the MCMC draws. The joint test for a structural break in the variance for all $m$ asset markets is based on the restriction $\sum_{i=1}^{m}\left(\Sigma_{i i, 1}>\Sigma_{i i, 0}\right)$, and is estimated by calculating the proportion of times $\Sigma_{1}-\Sigma_{0}>0$ in the MCMC draws.

The last type of structural break captures a change in tail behavior, or the third order moment of asset returns $i$ in regime $s_{t}=1$ compared to regime $s_{t}=0$ and is given by

$$
\omega_{i i, s_{t=0}} \neq \omega_{i i, s_{t=1}} .
$$

Yuan (2005) shows that borrowing constraints and information asymmetry can change the distribution of returns especially during downturns. While it is clear that in a crisis mean asset returns are expected to fall and volatility to rise, the direction of skewness change is less obvious. Ingersoll (1987), Shleifer and Vishney (1997), Harvey and Siddique (2000), Fry et al., (2010) and Conrad et al., (2013) suggest that skewness should change positively, while Black (1972), Bekaert and Wu (2000), Das and Uppal (2004) and Yuan (2005) suggest the opposite. Although our expectation is for positive skewness in a crisis, we recognize that both cases are possible so remain agnostic to the direction of change in the empirical work in Section 5. 
To examine the evidence for a structural break in the skewness for market $i$, across regimes $s_{t}=0$ and $s_{t}=1$, consider the hypothesis that $\omega_{i i, 1}=\omega_{i i, 0}$. This hypothesis can be recast to compare the unrestricted model $M_{u}$ and restricted $M_{r}$ models where $\omega_{i i, 1}=\omega_{i i, 0}$ is imposed. In $M_{u}$ all regime-specific parameters are free to vary across the two periods. $M_{r}$ features no shift in the return skewness for the asset market $i$ between the two regimes. This implies that under the restricted model return skewness in the two periods remains the same. Clearly, $M_{r}$ is nested within $M_{u}$ by setting $\omega_{i i, 1}=\omega_{i i, 0}$.

The Bayes factor comparing $M_{r}$ to $M_{u}$ for the skewness structural break is computed using the Savage-Dickey density ratio

$$
B F_{r u}=\frac{\pi\left(\omega_{i i, 1}-\omega_{i i, 0}=0 \mid y, M_{u}\right)}{\pi\left(\omega_{i i, 1}-\omega_{i i, 0}=0 \mid M_{u}\right)},
$$

where $\pi\left(\omega_{i i, 1}-\omega_{i i, 0}=0 \mid y, M_{u}\right)$ and $\pi\left(\omega_{i i, 1}-\omega_{i i, 0}=0 \mid M_{u}\right)$ are respectively the posterior and prior densities of $\omega_{i i, 1}-\omega_{i i, 0}$ evaluated at point 0 . Since the priors for $\omega_{i i, 0}$ and $\omega_{i i, 1}$ are assumed to be normal, with mean zero and variance $\phi_{\omega}$ (equation (16)), the denominator of equation (34) can be calculated, since the induced prior for $\omega_{i i, 1}-\omega_{i i, 0}$ is normal with mean zero and variance $2 \phi_{\omega}$. The numerator of this expression is estimated by averaging the quantity $\pi\left(\omega_{i i, 1}-\omega_{i i, 0}=0 \mid y, Z, \Sigma_{0}, \Sigma_{1}, s\right)$ in the MCMC draws.

The restricted model for the joint version of the test for the skewness break in all $m$ asset markets is $\omega_{i i, 0}=\omega_{i i, 1}, i=1, \ldots, m$, alternatively expressed as $\omega_{0}=\omega_{1}$. The Bayes factor is computed using the Savage-Dickey density ratio.

\subsection{Joint Contagion and Structural Breaks}

The flexibility of the RSSN model enables the testing of the joint contagion and structural breaks across all asset markets. The complete set of restrictions on the RSSN model for each case are summarized in the last row of each panel of Table 1.

In all of the joint tests, the RSSN model is the unrestricted model, with the sets of regime-specific parameters of $\mu_{0}$ and $\mu_{1}, \Sigma_{0}$ and $\Sigma_{1}$, and $\Omega_{0}$ and $\Omega_{1}$. The choice of restricted model $M_{r}$ for use in the calculation of the Bayes factor depends on which parameters have been constrained. For example, the restricted model for a joint structural break test based on shifts in the mean, variance and skewness is constructed by imposing the conditions $\mu_{i, 0}=\mu_{i, 1}, \Sigma_{i i, 0}=\Sigma_{i i, 1}$ and $\omega_{i i, 0}=\omega_{i i, 1}$. In this case the Bayes factor for comparing model $M_{r}$ with the unrestricted model $M_{u}$ is given by

$$
B F_{r u}=\frac{\pi\left(\mu_{i, 1}-\mu_{i, 0}=0, \Sigma_{i i, 1}-\Sigma_{i i, 0}, \omega_{i i, 1}-\omega_{i i, 0}=0 \mid y, M_{u}\right)}{\pi\left(\mu_{i, 1}-\mu_{i, 0}=0, \Sigma_{i i, 1}-\Sigma_{i i, 0}, \omega_{i i, 1}-\omega_{i i, 0}=0 \mid M_{u}\right)},
$$


where $\pi\left(\mu_{i, 1}-\mu_{i, 0}=0, \Sigma_{i i, 1}-\Sigma_{i i, 0}, \omega_{i i, 1}-\omega_{i i, 0}=0 \mid y, M_{u}\right)$ and $\pi\left(\mu_{i, 1}-\mu_{i, 0}=0, \Sigma_{i i, 1}-\Sigma_{i i, 0}, \omega_{i i, 1}-\omega_{i i, 0}=0 \mid M_{u}\right)$ are the posterior and prior densities for $\mu_{i, 1}-\mu_{i, 0}, \Sigma_{i i, 1}-\Sigma_{i i, 0}$ and $\omega_{i i, 1}-\omega_{i i, 0}$ evaluated at point 0 .

Equation (35) is slightly more difficult to evaluate. This is because although the prior for $\mu$ is normal (equation (16)) and $\Sigma_{0}$ is an inverse-Wishart density (equation $(22)), \pi\left(\mu_{i, 1}-\mu_{i, 0}=0, \Sigma_{i i, 1}-\Sigma_{i i, 0}, \omega_{i i, 1}-\omega_{i i, 0}=0 \mid y, M_{u}\right)$ is not a known density. Gaussian kernel estimates are used to approximate the two quantities

$\pi\left(\mu_{i, 1}-\mu_{i, 0}=0, \Sigma_{i i, 1}-\Sigma_{i i, 0}, \omega_{i i, 1}-\omega_{i i, 0}=0 \mid y, M_{u}\right)$ and $\pi\left(\mu_{i, 1}-\mu_{i, 0}=0, \Sigma_{i i, 1}-\Sigma_{i i, 0}, \omega_{i i, 1}-\omega_{i i, 0}=0 \mid M_{u}\right)$. The details of the Geweke's (2010) Gaussian kernel method for evaluating the densities are contained in Appendix C.

\section{Empirical Example}

This section applies the RSSN model of contagion to the Great Moderation and Global Financial Crisis periods. ${ }^{10}$ The data is outlined in Section 5.1. Details of the estimation of the RSSN model are contained in Section 5.2 and the results of the contagion and structural break tests are in Section 5.3. Sensitivity to the prior specification is undertaken in Section 5.4. Finally, the application is compared to the model for the Asian Financial Crisis in Section 5.5.

\subsection{US and European Data}

The data consists of US and European equity returns between January 4, 2005 to November 28, $2014(T=2585) .{ }^{11}$ Daily percentage returns are computed as the difference of the natural logarithms of the daily price indices, multiplied by 100 . All data series are denominated in US dollars. To account for time zone differences the US series is lagged by one period in comparison to the European data, and as is standard

\footnotetext{
${ }^{10}$ We have compared the proposed RSSN model to four popular time-varying volatility models using the marginal likelihood. The purpose of comparing the RSSN model to other models common in the literature is to demonstrate that the RSSN model provides a reasonable fit to the data relative to models which do not assume normality such as various GARCH models including the factor-GARCH, factor-ARCH, diagonal-vector-GARCH (DVEC-GARCH) and diagonal-vector-ARCH (DVEC-ARCH) models. The results confirmed the advantages of the RSSN model. In particular, the across-regime (crisis and non-crisis) comparisons can legitimately be emphasized.

${ }^{11}$ The data source is Datastream. The mnemonics are: France - France CAC 40 price index (FRCAC40); Germany - MDAX Frankfurt price index (MDAXIDX); Greece - Athex Composite price index (GRAGENL); Italy - FTSE MIB price index (FTSEMIB); US - Dow Jones Industrial price index (DJINDUS).
} 

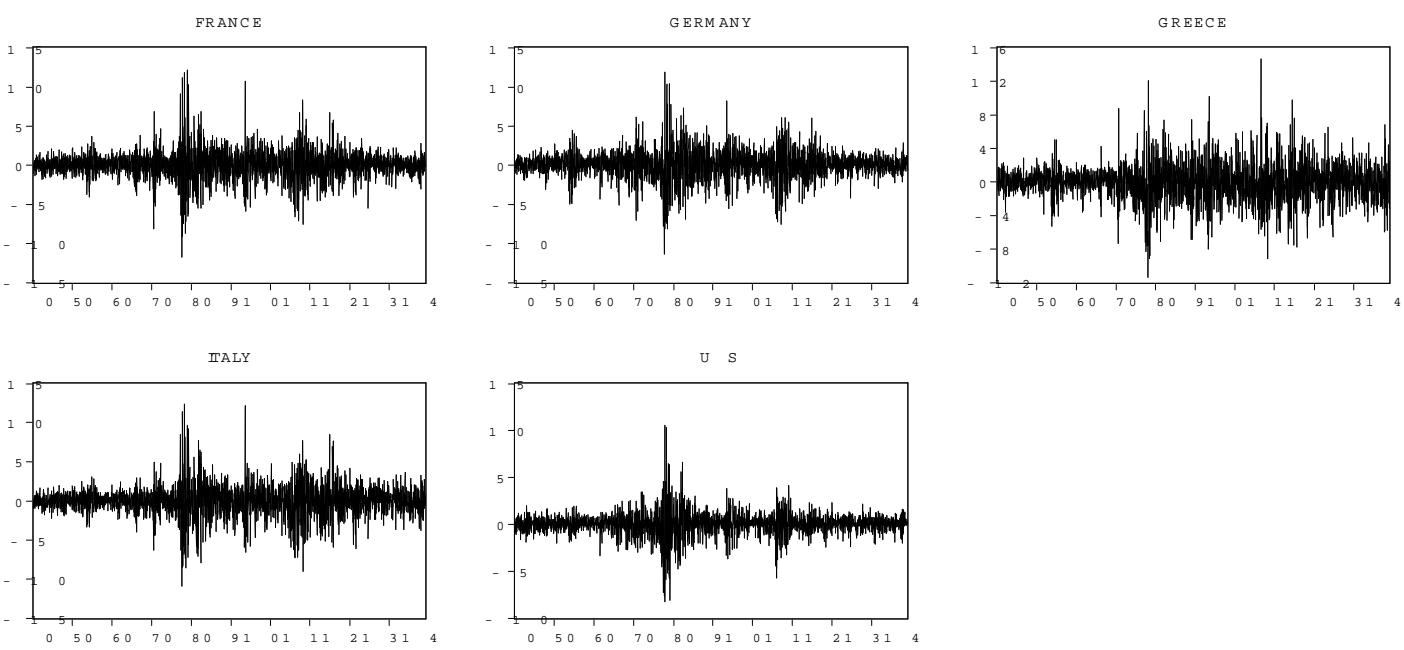

Figure 3: Daily percentage equity returns of selected markets in Europe and the US. Notes: The sample period is January 4, 2005 to November 28, 2014.

in the contagion literature the residuals of a $\operatorname{VAR}(5)$ are used as the data in the model. Time series plots of the returns are contained in Figure 3.

\subsection{RSSN Model Estimation}

As is customary, the prior hyperparameters in equations (16) to (18) are assumed to be known and are set to be $\underline{\beta}=0, \phi_{\mu}=0.01, \phi_{\omega}=1, \underline{\tau}_{\boldsymbol{\Sigma}}=20+m+1, \underline{S}_{\boldsymbol{\Sigma}}=$ $\left(\underline{\tau}_{\boldsymbol{\Sigma}}-m-1\right) \times \mathbf{I}_{m}$ with $m=5$. The prior variances are chosen to be relatively small so that the prior distributions are proper and relatively informative. Non-dogmatic beliefs about the likelihoods of a change in regime from the Great Moderation to the Global Financial Crisis occurring are incorporated formally via the prior probabilities $p_{i t}=\operatorname{Pr}\left(s_{t}=1 \mid s_{t-1}=i\right)$ for $i=0$ and 1 . To facilitate prior elicitation the simplifying assumption is that

$$
\operatorname{Pr}\left(s_{t}=1 \mid s_{t-1}=0\right)=\operatorname{Pr}\left(s_{t}=1 \mid s_{t-1}=1\right)=p_{t} .
$$

Specification of the prior makes it easy to incorporate information about the timing of a regime change. Specifically, the initial value for the probability of being in regime 0 is set to $\operatorname{Pr}\left(s_{t}=0\right)=0.99$ during the period from January 5, 2005 to July 25, 2007. Mid 2007 is when vulnerabilities in the subprime mortgage markets first arose with the Fed's first policy response to the crisis in August with the provision of liquidity to financial markets as money and credit markets began experiencing dislocation (Board 


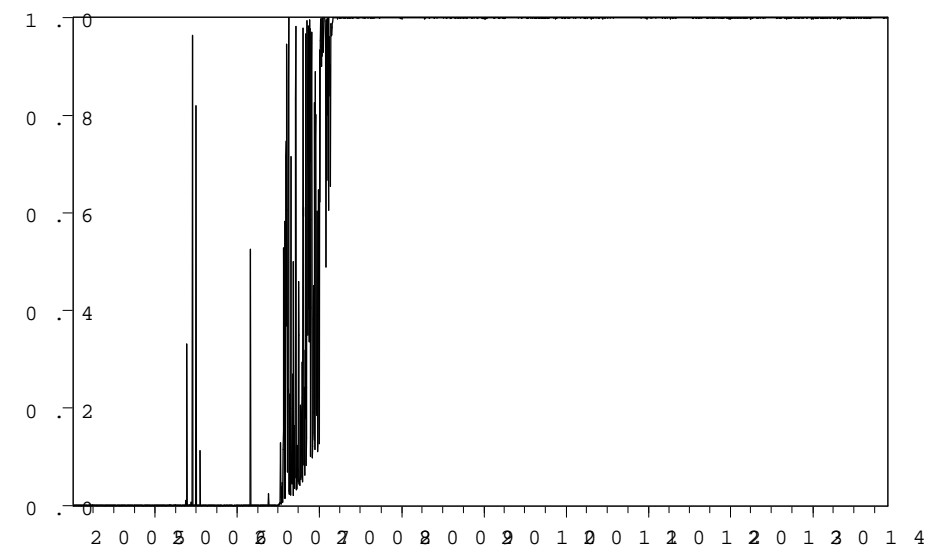

Figure 4: Probability of being in the Global Financial Crisis regime. Notes: The sample period is January 4, 2005 to November 28, 2014.

of the Governors of the Federal Reserve System, 2007). The probability of being in regime 1 is set to $\operatorname{Pr}\left(s_{t}=1\right)=0.99$ during the period between March 3, 2008 and November 27, 2014. March 2008 coincides with the bail out of Bear Stearns. The probability of being in regime 0 decreases linearly from 0.99 on July 26, 2007 to 0.01 on March 3, 2008, by a margin of $\left(\frac{1}{157} \times(0.99-0.01)\right)$ per day. For instance, the probability of being in regime 0 on July 2,2007 is $0.99-\left(\frac{1}{157} \times(0.99-0.01)\right)$ where there are 157 days between July 25, 2007 and March 3, 2008. Robustness to the choice of prior is explored in Section 5.4.

For estimation purposes, the coskewness matrix $\Omega$ in equation (1) is restricted to be a symmetric matrix, which means the dimension of $\omega$ reduces from $k=m^{2}$ to $k=m(m+1) / 2$. Furthermore, the constant term $c$ in equation (3) is set to $-\sqrt{2 / \pi}$ so that $E\left(Z_{t}\right)=0$ and $V\left(Z_{t}\right)=(\pi-2) / \pi$, and the inclusion of the latent variables $Z_{t}$ does not affect the (unconditional) expectation of $y_{t}$. In the original specification of Sahu et al., (2003), c is set to be zero.

The Gibbs-sampling described in Appendix A is applied to the RSSN model. The first 20,000 draws are discarded in order to allow the Markov Chain to converge to a stationary distribution. To reduce sample autocorrelation and to avoid biased Monte Carlo standard errors, every 10 draws for the next 200, 000 iterations are recorded for a total of 20,000 draws which are used to calculate the posterior summaries. The criteria for choosing independent draws is based on the inefficiency factors of the switching parameters with the details shown in Appendix D. The MCMC algorithm is well 
behaved for the RSSN model with Table 8 in the Appendix showing that the inefficiency factors are low for all switching parameters.

Figure 4 presents the probability that the model is in a particular regime over the sample period. Inspection of the figure shows that equity markets briefly attempted to transition to a new regime in mid January 2006, perhaps reflecting the emerging pressures in the subprime market. However, the regime change becomes increasingly evident in January of 2007, and consistently so by the February of 2008. The transition between the regimes is volatile as the regime switches between the alternatives, even before the key crisis trigger of the collapse of Bear Stearns in March 2008 before finally settling into the Global Financial Crisis regime.

Table 3 presents the posterior means of the regime-switching parameters when innovations are fitted to the RSSN model of contagion. The first panel of the table presents the results for regime $s_{t}=0$, while the second panel presents the results for regime $s_{t}=1$. The parameters for correlation and coskewness all appear to change across the regimes. The correlation of the pairs of markets is higher when $s_{t}=1$ than when $s_{t}=0$ for all pairs of markets. For coskewness two patterns emerge. First, coskewness between almost all pairs of markets becomes less negative in the Global Financial Crisis period compared to the Great Moderation regime, reflecting the preference of risk averse investors for positive coskewness in a crisis period (Guidolin and Timmerman, 2008 and Fry et al., 2010). The anomaly is for the value of coskewness for the Greece-Italy pair which falls from -0.383 to -0.472 . This combination is the only pair to exhibit an increase in negative coskewness across the regimes.

Second, the coskewness statistics of the US returns with all of the European returns change the most, with a switch from negative values ranging between -0.187 for the Germany-US pair to -0.156 for the Italy-US pair when $s_{t}=0$, to mainly positive values of 0.018 for France-US, 0.105 for Italy-US, and 0.898 for Greece-US which is the largest coefficient. The exception is for the Germany-US pair when $s_{t}=1$ which remains negative at -0.009 , reflecting that investors are less risk averse in the German market relative to the US than they are in the other European markets.

In terms of the moments, mean returns are positive for all markets in the Great Moderation, while in the Global Financial Crisis they are negative for France, Greece and Italy, but positive for the larger economies of Germany and the US. The variances of equity returns for the European markets are higher by a factor of around 10 in the Global Financial Crisis regime. The variance of the US returns increase as well 
Table 4:

Posterior means of the switching parameters.

\begin{tabular}{|c|c|c|c|c|c|c|}
\hline Parameters & Markets & France & Germany & Greece & Italy & US \\
\hline \multicolumn{7}{|c|}{ Great Moderation regime $\left(s_{t}=0\right)$} \\
\hline \multirow[t]{4}{*}{ Covariance $\left(\Sigma_{i j, 0}\right)$} & Germany & 0.299 & & & & \\
\hline & Greece & 0.150 & 0.193 & & & \\
\hline & Italy & 0.288 & 0.246 & 0.148 & & \\
\hline & US & 0.109 & 0.067 & -0.013 & 0.089 & \\
\hline \multirow{4}{*}{ Correlation $\left(\rho_{i j, 0}\right)$} & Germany & 0.681 & & & & \\
\hline & Greece & 0.319 & 0.380 & & & \\
\hline & Italy & 0.743 & 0.580 & 0.329 & & \\
\hline & US & 0.280 & 0.157 & -0.032 & 0.236 & \\
\hline \multirow[t]{4}{*}{ Coskewness $\left(\omega_{i j, 0}\right)$} & Germany & -0.653 & & & & \\
\hline & Greece & -0.423 & -0.569 & & & \\
\hline & Italy & -0.536 & -0.593 & -0.383 & & \\
\hline & US & -0.168 & -0.187 & -0.158 & -0.156 & \\
\hline $\operatorname{Mean}\left(\mu_{i=0}\right)$ & & 0.044 & 0.079 & 0.066 & 0.025 & 0.031 \\
\hline Variance $\left(\Sigma_{i i, 0}\right)$ & & 0.399 & 0.469 & 0.525 & 0.368 & 0.367 \\
\hline Skewness $\left(\omega_{i i, 0}\right)$ & & -0.586 & -0.761 & -0.880 & -0.488 & -0.072 \\
\hline \multicolumn{7}{|c|}{ Global Financial Crisis regime $\left(s_{t}=1\right)$} \\
\hline \multirow[t]{4}{*}{ Covariance $\left(\Sigma_{i j, 1}\right)$} & Germany & 3.257 & & & & \\
\hline & Greece & 2.850 & 2.799 & & & \\
\hline & Italy & 3.611 & 3.366 & 3.037 & & \\
\hline & US & 1.530 & 1.468 & 1.515 & 1.611 & \\
\hline \multirow{4}{*}{ Correlation $\left(\rho_{i j, 1}\right)$} & Germany & 0.929 & & & & \\
\hline & Greece & 0.660 & 0.656 & & & \\
\hline & Italy & 0.938 & 0.886 & 0.649 & & \\
\hline & US & 0.824 & 0.800 & 0.672 & 0.800 & \\
\hline \multirow[t]{4}{*}{ Coskewness $\left(\omega_{i j, 1}\right)$} & Germany & -0.016 & & & & \\
\hline & Greece & -0.403 & -0.398 & & & \\
\hline & Italy & 0.036 & -0.047 & -0.472 & & \\
\hline & US & 0.018 & -0.009 & 0.898 & 0.105 & \\
\hline Mean $\left(\mu_{i=1}\right)$ & & -0.017 & 0.020 & -0.074 & -0.037 & 0.018 \\
\hline Variance $\left(\Sigma_{i i, 1}\right)$ & & 3.551 & 3.463 & 5.253 & 4.172 & 0.971 \\
\hline Skewness $\left(\omega_{i i, 1}\right)$ & & 0.061 & -0.230 & -0.655 & -0.253 & -1.018 \\
\hline
\end{tabular}

Notes: posterior means of the covariance, correlation, coskewness, mean, variance and skewness in the Great Moderation and Global Financial Crisis regimes for the equity returns of selected markets in Europe and the US. The sample period is January 4, 2005 to November 27, 2014. 
but by a smaller magnitude. Interestingly, the skewness parameters of the equity returns of Europe are all negative in regime $s_{t}=0$ but become smaller in magnitude as skewness reduces. Skewness falls from -0.761 to -0.230 for Germany, -0.880 to -0.655 for Greece, and -0.488 to -0.253 for Italy. The direction of change is the same for France although skewness for France changes sign (-0.586 to 0.061). Skewness in the US becomes more negative in the Global Financial Crisis, changing from -0.072 to -1.018 as investors see the US as relatively safe compared to Europe.

\subsection{Contagion and Breaks During the Global Financial Crisis}

Table 5 presents the empirical results for the tests for contagion and structural breaks that are summarized in Table 2 between the US equity returns and the selected equity returns of the European countries. The table consists of three panels: the first examines the evidence of contagion between the US and Europe through the correlation and coskewness parameters; the second examines evidence of the moment structural breaks in the mean, variance and skewness parameters of each asset return; and the third considers a joint test of all of the contagion and structural break parameters.

Evidence of Contagion The first panel of Table 4 shows that the probability of contagion as reflected by an increase in the traditional correlation coefficient between all combinations of the US and European returns is $100 \%$ in the Global Financial Crisis compared to the Great Moderation. The correlation channel of contagion dominates the coskewness channel as the coskewness change is not significant for almost all of the countries in the sample. There is decisive support for coskewness contagion occurring between the US and Greek returns, with the value of the $\log$ of the Bayes factor $\ln \left(B F_{r u}\right)$ being -127.06 . This result reveals the preferences of risk averse investors in moving away from Greek to US assets when in the crisis regime. The asset returns of the remaining European countries of France, Germany and Italy are relatively stable across the regimes, indicating the relative severity of contagion in Greece compared to the rest of Europe. The joint tests for contagion between the US and all European markets through each of the correlation and the coskewness comoments are contained in the last column of Table 5. The probability of contagion occurring jointly through the correlation channel is $100 \%$, while there is decisive evidence of contagion through coskewness with a value of the $\log$ of the Bayes factor $\ln \left(B F_{r u}\right)$ of -39.68 .

The bottom row of the first panel of the Table presents the results for the test 
Table 5:

Empirical results of the contagion and structural break tests for the equity returns of selected markets in Europe and the US in the Global Financial Crisis.

\begin{tabular}{|c|c|c|c|c|c|c|c|}
\hline Tests & $\begin{array}{l}\text { Method } \\
\text { (DR) }\end{array}$ & France & Germany & Greece & Italy & US & $\forall i$ \\
\hline \multicolumn{8}{|c|}{ Contagion tests $(i \neq j)$} \\
\hline Correlation & $p$ & 1.00 & 1.00 & 1.00 & 1.00 & & 1.00 \\
\hline Coskewness & $B F$ & 1.31 & 1.33 & -127.06 & 0.73 & & -39.68 \\
\hline $\begin{array}{l}\text { Corr. } \\
\text { \&coskew. }\end{array}$ & $B F$ & -105.86 & -97.27 & -166.87 & -102.72 & & -56.17 \\
\hline \multicolumn{8}{|c|}{ Structural break tests $(i)$} \\
\hline Mean & $p$ & 0.86 & 0.85 & 0.12 & 0.89 & 0.99 & 1.00 \\
\hline Variance & $p$ & 1.00 & 1.00 & 1.00 & 1.00 & 1.00 & 1.00 \\
\hline Skewness & $B F$ & 0.09 & 0.33 & 0.31 & -0.59 & -34.92 & -69.21 \\
\hline $\begin{array}{l}\text { Mean,var. } \\
\text { \&skew. }\end{array}$ & $B F$ & -2182.60 & -1524.20 & -2877.30 & -1627.60 & -188.30 & -8279.30 \\
\hline \multicolumn{8}{|c|}{ Joint contagion $(i \neq j)$ and structural break tests $(i)$} \\
\hline All & $B F$ & -231.99 & -196.79 & -456.55 & -199.70 & & -8335.50 \\
\hline
\end{tabular}

Notes: The sample period is January 4, 2005 to 27 November, 2014. Contagion is measured with respect to the US. See Table 2 for a summary of the tests and Section 4 for details. The method of hypothesis evaluation (DR) for each test is indicated in the table. $p$ denotes that a decision is probability based. $B F$ denotes that a decision is based on the Bayes Factor using the model selection evidence categories in Table 3. Evidence of contagion or a structural break is indicated by bold font in the table. 
that contagion occurs jointly through both the correlation and coskewness parameters. This is the case for all country pairs with decisive evidence of contagion through the two channels, with the $\log$ of the Bayes factor $\ln \left(B F_{r u}\right)$ ranging between -166.87 for the Greece-US pair to -97.27 for the Germany-US pair. When considering the joint test for $\forall i$, the value of the natural logarithm of the Bayes factors $\ln \left(B F_{r u}\right)$ is -56.17 showing decisive evidence of joint correlation and coskewness based contagion.

Evidence of Structural Breaks The result that stands out for the structural break tests shown in the first panel of Table 5 is that there is evidence for a structural break in all of the moments of the mean, variance and skewness for the US in the Global Financial crisis period. The US is the only country in the sample with decisive evidence of a structural break in the skewness parameter with the value of natural log of the Bayes factor $\ln \left(B F_{r u}\right)$ of -34.92 . As shown in Table 4 containing the posterior means of the parameters, the skewness parameter in the US becomes more negative in the Global Financial Crisis, changing from -0.072 to -1.018 . The tests indicate a flight to safety of risk averse investors that is independent of the comoments of the asset returns of Europe with the US. Investors display relatively more risk appetite for US assets during the Global Financial Crisis period.

The probabilities of a structural break in the mean for France, Germany and Italy are 86,85 and $89 \%$ respectively, while for Greece the probability of a change in the mean is only $12 \%$. Further, there is no evidence of a structural break in skewness for the European countries considered individually. Although France, Germany, Greece and Italy are not affected by a structural break in the first or third moments, they are affected by structural breaks in the second order moment. The European markets are individually affected by a break in the variance with probabilities for all markets of $100 \%$.

Considering all $m$ markets jointly, there is evidence for a structural break in the mean in the Global Financial Crisis regime compared to the Great Moderation with a probability of $100 \%$. The higher order moment breaks are also evident jointly. The probability of the joint structural break in the variance is $100 \%$, and there is decisive evidence of a structural break in skewness with the value of natural log of the Bayes factor $\ln \left(B F_{r u}\right)$ of -69.21 . The joint test of the mean, variance and skewness structural breaks for each country and for the countries considered jointly show decisive evidence of structural breaks. Overall, the results for the moment break tests show that it is 
the structural break in the variance which is most important for all markets, followed equally by the mean and skewness break just for the US. However, when considered jointly all moment break tests are significant.

Evidence of Joint Contagion and Structural Breaks The third panel of Table 5 provides evidence on the significance of the operation of contagion and structural breaks simultaneously for each market $i$ as well as for all of the markets jointly. The bottom row, and particularly the last column of the bottom row can be thought of as a test of all channels of comoment and moment change and can be thought of as an overall test for a crisis and contagion. For the individual markets the evidence of joint contagion and structural breaks is decisive in all cases with the value of the natural logarithm of the Bayes factor ranging between -456.55 for Greece, to -196.79 for Germany. For the combined markets $\ln \left(B F_{r u}\right)$ is -8335.50 indicating the importance of examining contagion and structural breaks jointly.

\subsection{Sensitivity to Priors}

The priors of the dates of when the Great Moderation ends and when the Global Financial Crisis begins are chosen to be strong given the dramatic nature of the events in financial markets first originating in the US. This section examines the sensitivity of the model by reducing the priors of being in the Great Moderation and Global Financial Crisis regimes respectively. If the priors are set up as $\operatorname{Pr}\left(s_{t}=0\right)=0.80$ before July 25, 2007 rather than $\operatorname{Pr}\left(s_{t}=0\right)=0.99$ and if $\operatorname{Pr}\left(s_{t}=1\right)=0.80$ rather than $\operatorname{Pr}\left(s_{t}=1\right)=0.99$ for the period March 3, 2008 to November 27, 2014, then there is more volatility in the probability of being in a particular regime as shown in Figure 5. The results of reestimating the contagion and structural break tests in the RSSN model with the relaxed priors are contained in Table 6 . Comparison of Table 6 with the original results in Table 5 shows that the tests for contagion and structural breaks are almost qualitatively the same, with the differences being that the structural break in the mean is no longer significant for the US or for $\forall i$ markets.

\subsection{Comparison to the Asian Financial Crisis}

Most financial market crises of the past three decades are of short duration, sometimes only being days or weeks (see Fry-McKibbin et al., 2014 for a comparison of crisis duration for those occurring in the last 20 years). The exception is the Asian Financial 


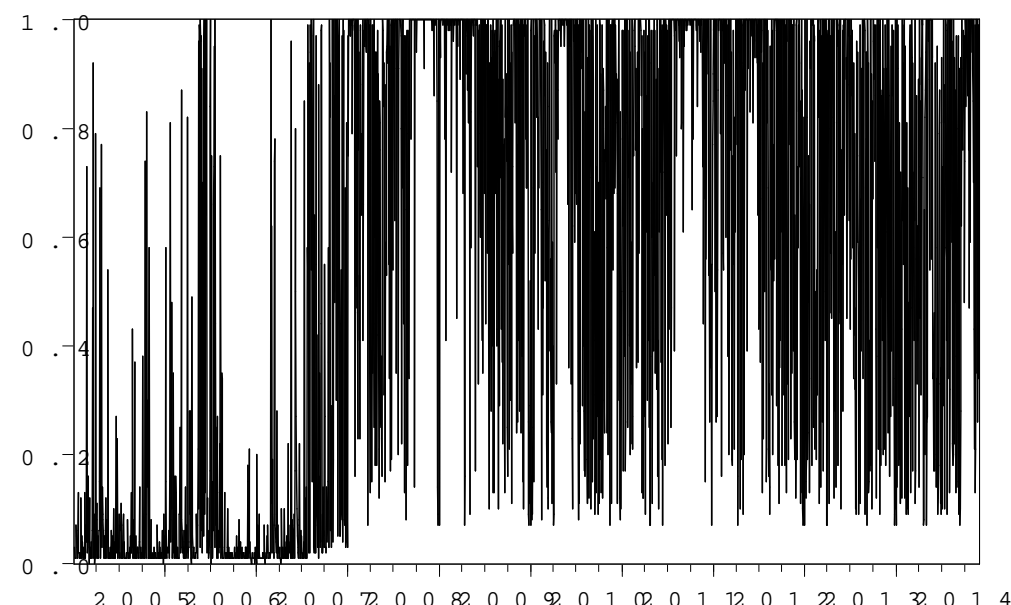

Figure 5: Probability of being in the Global Financial Crisis regime with relaxed priors. Notes: The sample period is January 4, 2005 to November 28, 2014.

Table 6:

Empirical results of the contagion and structural break tests for the equity returns of selected markets in Europe and the US in the Global Financial Crisis with relaxed priors outlined in Section 5.4.

\begin{tabular}{|c|c|c|c|c|c|c|c|}
\hline Tests & $\begin{array}{c}\text { Method } \\
\text { (DR) }\end{array}$ & France & Germany & Greece & Italy & US & $\forall i$ \\
\hline \multicolumn{8}{|c|}{ Contagion tests $(i \neq j)$} \\
\hline Correlation & $p$ & 1.00 & 1.00 & 1.00 & 1.00 & & 1.00 \\
\hline Coskewness & $B F$ & 0.68 & 0.46 & -7.60 & 0.33 & & -38.03 \\
\hline $\begin{array}{l}\text { Corr. } \\
\text { \&coskew. }\end{array}$ & $B F$ & -79.11 & -76.55 & -55.07 & -75.29 & & -41.22 \\
\hline \multicolumn{8}{|c|}{ Structural break tests $(i)$} \\
\hline Mean & $p$ & 0.08 & 0.00 & 0.00 & 0.07 & 0.71 & 0.34 \\
\hline Variance & $p$ & 1.00 & 1.00 & 1.00 & 1.00 & 1.00 & 1.00 \\
\hline Skewness & $B F$ & 0.22 & 0.03 & 0.47 & -0.73 & -3.10 & -14.76 \\
\hline $\begin{array}{l}\text { Mean,var. } \\
\text { \&skew. }\end{array}$ & $B F$ & -1337.60 & -786.30 & -3196.00 & -746.70 & -187.20 & -6077.80 \\
\hline \multicolumn{8}{|c|}{ Joint contagion $(i \neq j)$ and structural break tests $(i)$} \\
\hline All & $B F$ & -159.41 & -136.22 & -250.27 & -128.50 & & -6119.00 \\
\hline
\end{tabular}

Notes: The sample period is January 4, 2005 to 27 November, 2014. Contagion is measured with respect to the US. See Table 2 for a summary of the tests and Section 4 for details. The method of hypothesis evaluation (DR) for each test is indicated in the table. $p$ denotes that a decision is probability based. $B F$ denotes that a decision is based on the Bayes Factor using the model selection evidence categories in Table 2. Evidence of contagion or a structural break is indicated by bold font in the table. 
Crisis which is the second longest in duration after the Global Financial Crisis. Most authors define the Asian Financial Crisis period of at least six months and up to a year making it a relevant comparator.

The model described in equations (7) to (9) is applied to the Asian equity markets of Hong Kong, Japan, Korea, Malaysia and Thailand around the time of the speculative attack on Hong Kong currency and equity markets. The sample period extends from January 11, 1995 to December 31, 1998. The prior for the crisis regime is set to $\operatorname{Pr}\left(s_{t}=1\right)=0.99$ during the period between October 20, 1997 and December 31, 1998. October 20 is the date of the speculative attack. ${ }^{12}$ The prior of the non-crisis regime $\operatorname{Pr}\left(s_{t}=0\right)=0.99$ from January 11, 1995 to December 31, 1996. The probability of being in regime $s_{t}=0$ decreases linearly from 0.99 on January 1, 1997 to 0.01 on October 19, 1997.

Figure 6 presents the probability of the Asian equity markets being in a non-crisis regime or the Asian Financial Crisis regime while Table 7 presents the contagion and structural break tests. ${ }^{13}$ Inspection of Figure 6 shows that the regime change is evident by mid 1997 and is consistently in the crisis regime by the time of the speculative attack. Like the case for the Great Moderation and the Global Financial Crisis period, transitioning between the two regimes is by no means smooth, reflecting the uncertainty in financial markets even before the speculative attack.

The results for the Asian Financial Crisis validate those for Europe and the US during the Global Financial Crisis. The channels of contagion and structural breaks that are significant during the Asian Financial Crisis are similar to those for the Global Financial Crisis. Correlation based contagion is significant for all markets and dominates coskewness based contagion which is only significant for Malaysia. Unlike other countries affected by the Asian Financial Crisis, Malaysia made abrupt changes to policies affecting international investor by instituting capital controls as a way to contain the crisis. The change in policies affecting investors is perhaps a reason for the significance of coskewness for Malaysia with respect to Hong Kong. Japan has a similar role of being the destination of a flight to safety of risk averse investors to that of the US in the first application as shown by the significance of each moment of the mean, variance and skewness. Changes in these parameters are significant with $99 \%$ and $100 \%$ proba-

\footnotetext{
${ }^{12}$ An alternative starting date would be July 2, 1997 corresponding to the devaluation of the Thai baht, however the equity focus of this paper makes the Hong Kong speculative attack the relevant date and is consistent with Forbes and Rigobon (2002).

${ }^{13}$ The posterior means of the regime switching parameters are available on request.
} 


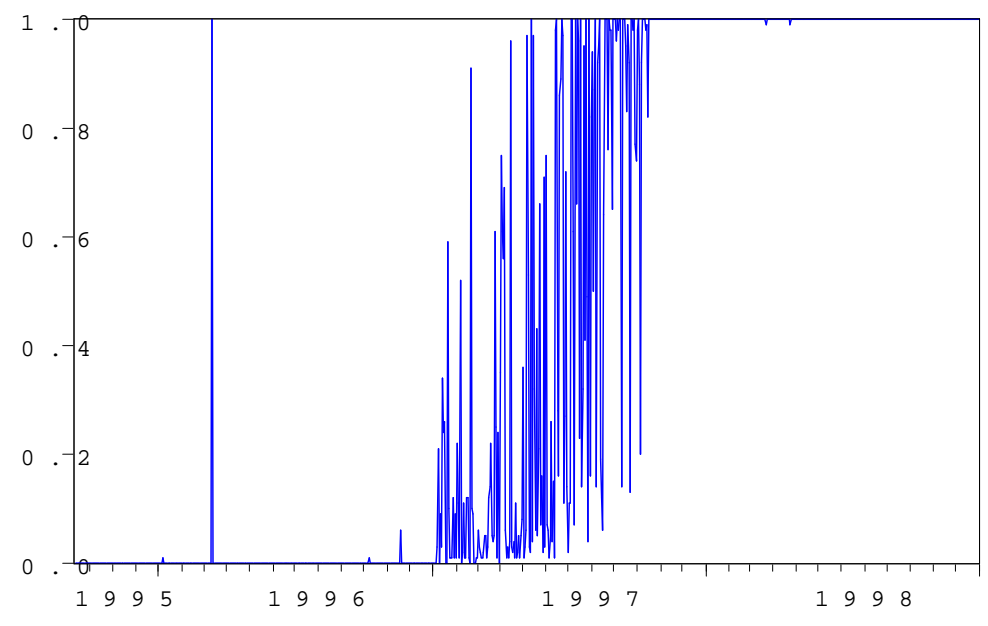

Figure 6: Probability of being in the Asian Financial Crisis Regime. Notes: The sample period is September 12, 1995 to December 31, 1998.

bility respectively for the mean and the variance, while there is decisive evidence of a structural break in skewness with a value of natural log of the Bayes factor $\ln \left(B F_{r u}\right)$ of -29.51. As it is for the application to the Global Financial Crisis the structural break in the variance is significant across the board, with less evidence for a structural break in the mean with the exception of Korea in addition to Japan. The evidence again suggests that it is important to account for joint contagion and structural breaks.

\section{Conclusions}

In crisis periods, policy makers and investors are challenged by the need to understand how asset return comovements might change compared to normal times. Decisions need to be made relating to portfolio allocation and shock mitigation in being domestically oriented, internationally oriented or both. This paper develops a regime switching skew-normal (RSSN) model of crisis and contagion by building upon Hamilton (1989) by relaxing the assumption of multivariate normality with a multivariate skew-normal distribution in its place. Contagion is defined through changes in the comoments of correlation and coskewness in the non-crisis regime compared to a crisis regime. Tests for structural breaks in the moments of the mean, variance and skewness are also specified. Including higher order moments and comoments better reflects the characteristics of financial returns data observed in both crisis periods and normal times. The extensions 
Table 7:

Empirical results of the contagion and structural break tests for the equity returns of selected Asian markets in the Asian Financial Crisis.

\begin{tabular}{|c|c|c|c|c|c|c|c|}
\hline Tests & $\begin{array}{c}\text { Method } \\
\text { (DR) }\end{array}$ & Japan & Korea & Malay. & Thai. & HK. & $\forall i$ \\
\hline \multicolumn{8}{|c|}{ Contagion tests $(i \neq j)$} \\
\hline Correlation & $p$ & 0.96 & 1.00 & 0.96 & 0.95 & & 1.00 \\
\hline Coskewness & $B F$ & 0.52 & 0.33 & -1.22 & -0.88 & & -345.90 \\
\hline Corr\&coskew & $B F$ & -0.84 & -9.87 & -0.48 & -0.50 & & -369.84 \\
\hline \multicolumn{8}{|c|}{ Structural break tests $(i)$} \\
\hline Mean & $p$ & 0.96 & 0.99 & 0.12 & 0.86 & 0.61 & 0.49 \\
\hline Variance & $p$ & 1.00 & 1.00 & 1.00 & 1.00 & 1.00 & 1.00 \\
\hline Skewness & $B F$ & -29.51 & -0.29 & -0.26 & -0.10 & -0.09 & -39.46 \\
\hline $\begin{array}{l}\text { Mean,var, } \\
\text { \& skew. }\end{array}$ & $B F$ & -49.77 & -89.78 & -434.25 & -187.89 & -54.39 & -782.84 \\
\hline \multicolumn{8}{|c|}{ Joint contagion $(i \neq j)$ and structural break tests $(i)$} \\
\hline All & $B F$ & -41.87 & -72.33 & -67.96 & -40.67 & & -1147.70 \\
\hline
\end{tabular}

Notes: The sample period is January 4, 2005 to 27 November, 2014. Contagion is measured with respect to Hong Kong. See Table 2 for a summary of the tests and Section 4 for details. The method of hypothesis evaluation (DR) for each test is indicated in the table. $p$ denotes that a decision is probability based. $B F$ denotes that a decision is based on the Bayes Factor using the model selection evidence categories in Table 3. Evidence of contagion or a structural break is indicated by bold font in the table. 
of the model to include coskewness based contagion and structural breaks in skewness are important as risk averse investors prefer positive coskewness and positive skewness, making these moments relevant to the crisis regime. Compared to other frameworks of contagion which are often conducted on a bivariate basis, evidence of joint contagion or structural breaks across the $m$ asset returns is also assessed.

The regime switching nature of the model allows the crisis timing to be endogenous to the model, eliminating the problems inherent in the a priori specification of the crisis period by researchers, and the distributional assumption allows the specification of both linear and non-linear features of contagion and structural breaks. The model is estimated and hypotheses evaluated using Bayesian model estimation techniques. The model is applied to the regimes of the Great Moderation and the Global Financial Crisis for the US and selected European equity returns, and is compared to the Asian Financial Crisis which is of a long duration and the best comparator for the Global Financial Crisis.

The empirical results for the model applied to European and US equity markets from 2005-2014 as well as to the model applied to the Asian equity markets from 19951998 have qualitatively similar results. First, the transition between the non-crisis regime to the crisis regime is volatile for both applications. Equity markets show evidence of a shift towards a crisis state before the key triggers of the collapse of Bear Stearns in March 2008 and the speculative attack on the Hong Kong equity market in October 1998. Second, contagion measured through the traditional correlation coefficient is significant in all cases, validating the use of the correlation coefficient as a first measure of contagion. Third, coskewness contagion is significant for one country pair in each case. These are the Greece-US pair for the Global Financial Crisis and the Malaysia-Hong Kong pair for the Asian Financial Crisis. Greece and Malaysia have in common that their policy responses changed the circumstances for international investors investing in the respective countries, Greece through their sovereign default, and Malaysia through the imposition of capital controls. Fourth, inspection of the moment statistics suggests a flight to safety to the major markets of the US during the Global Financial Crisis, and to Japan during the Asian Financial Crisis. While all markets were affected by a significant change in volatility in the crisis periods, only the US and Japan also showed evidence of breaks in the mean and skewness moments. The results indicate that risk averse investors had more risk appetite for US and Japanese assets during the crisis regimes, compared to their counterparts in either Europe or 
Asia. The flight to safety is true even when the US is a source of crisis in the first place. Finally, all channels of contagion and structural breaks are significant when considered jointly, reinforcing the need to consider contagion and structural breaks during crises in a multivariate setting.

\section{References}

[1] Adrian, T., Crump, R.K., and Vogt, E. (2015), "Nonlinearity and Flight to Safety in the Risk-Return Trade-Off for Stocks and Bonds," FRB of NY Staff Report No. 723.

[2] Allegret, J.-P., Raymond, H., and Rharrabti, H., (2017), "The Impact of the European Sovereign Debt Crisis on Banks Stocks. Some Evidence of Shift Contagion In Europe," Journal of Banking \& Finance, 74, 24-37.

[3] Ang, A., and Bekaert, G. (2002), "International Asset Allocation with Regime Shifts," Review of Financial Studies, 15, 4, 1137-87.

[4] Ang, A., and Timmermann, A. (2011), "Regime Changes and Financial Markets," Annual Review of Financial Economics, 4, 313-37.

[5] Baele, L., Bekaert, G., Inghelbrecht, K., and Wei, M. (2013), "Flights to Safety," NBER Working Paper, No. 19095.

[6] Baur, D.G., and Lucey, B.M., (2009), "Flights and Contagion-An Empirical Analysis of Stock-Bond Correlations," Journal of Financial Stability 5, 339-352.

[7] Bekaert, G., and Wu, G. (2000), "Asymmetric Volatility and Risk in Equity Markets," The Review of Financial Studies, 13, 4-42.

[8] Bekaert, G., Ehrmann, M., Fratzscher, M., and Mehl, A. (2014), "The Global Crisis and Equity Market Contagion," The Journal of Finance, 69, 2597-2649.

[9] Billio, M., and Caporin, M. (2005), "Multivariate Markov Switching Conditional Correlation GARCH Representations for Contagion Analysis," Statistical Methods and Applications, 14, 145-61.

[10] Black, F. (1972), "Capital Market Equilibrium with Restricted Borrowing," Journal of Business, 45, 444-54.

[11] Board of the Governors of the Federal Reserve System (2007), FRB: Press ReleaseFOMC Statement: The Federal Reserve Is Providing Liquidity to Facilitate the Orderly Functioning of Financial Markets-August 10, 2007.

[12] Calvo, G.A., and Mendoza, E.G. (2000), "Rational Contagion and The Globalization Of Securities Markets," Journal of International Economics 51, 79-113. 
[13] Chan, J., Henderson, D., Parmeter, P. and Tobias, J. (2017), "Nonparametric Estimation in Economics: Bayesian and Frequentist Approaches," WIREs Computational Statistics, forthcoming.

[14] Chib, S. (1995), "Marginal Likelihood from the Gibbs Output," Journal of the American Statistical Association, 90, 1313-21.

[15] Chib, S. (1996)., "Calculating Posterior Distributions and Modal estimates in Markov Mixture Models," Journal of Econometrics, 75, 79-97.

[16] Chib, S., and Jeliazkov, I. (2001), "Marginal Likelihood From the MetropolisHastings Output," Journal of the American Statistical Association, 96, 270-81.

[17] Conrad, J., Dittmar, R.F., and Ghysels, E. (2013), "Ex Ante Skewness and Expected Stock Returns," Journal of Finance, 68, 85-124.

[18] Contessi, S., De Pace, P., and Guidolin, M. (2014), "How did the Financial Crisis alter the Correlations of U.S. Yield Spreads?" Journal of Empirical Finance, 28, $362-385$.

[19] Das, S.R., and Uppal, R. (2004), "Systemic Risk and International Portfolio Choice," The Journal of Finance, 59, 2809-2834.

[20] Dickey, J.M. (1971), "The Weighted Likelihood Ratio, Linear Hypotheses on Normal Location Parameters," The Annals of Mathematical Statistics, 204-223.

[21] Dungey, M., Milunovich, G., Thorp, S., and Yang, M. (2015), "Endogenous Crisis Dating and Contagion using Smooth Transition Structural GARCH," Journal of Banking \& Finance, 58, 71-79.

[22] Ehrmann, M., and Fratzscher, M. (2017), "Euro Area Government Bonds - Fragmentation and Contagion During The Sovereign Debt Crisis," Journal of International Money and Finance, 70, 26-44.

[23] Escobar, M.D. (1994), "Estimating Normal Means with a Dirichlet Process Prior," Journal of the American Statistical Association, 89, 268-277.

[24] Escobar, M.D. and West, M (1995), "Bayesian Density Estimation and Inference Using Mixtures," Journal of the American Statistical Association, 90, 577-588.

[25] Forbes, K.J., and Rigobon, R. (2002), "No Contagion, Only Interdependence: Measuring Stock Market Comovements," The Journal of Finance, 57, 5, 2223-61.

[26] Frühwirth-Schnatter, S. (2006), Finite Mixture and Markov Switching Models, Springer, New York.

[27] Fry-McKibbin, R.A., and Hsiao, C.Y. (2018), "Extremal Dependence and Contagion" Econometric Reviews, 37, 6, 626-649.

[28] Fry-McKibbin, R.A., Martin, V.L., and Tang, C. (2014), "Financial Contagion and Asset Pricing," Journal of Banking $6 \mathcal{G}$ Finance, 47, 296-308. 
[29] Fry, R.A., Martin, V.L., and Tang, C. (2010), "A New Class of Tests of Contagion with Applications," Journal of Business and Economic Statistics, 28, 3, 423-36.

[30] Geweke. J. (1991), "Efficient Simulation from the Multivariate Normal and Student-t Distributions Subject to Linear Constraints and the Evaluation of Constraint Probabilities", Computing Science and Statistics: Proceedings of the 23rd Symposium on the Interface, 571-78.

[31] Geweke. J. (2010), Complete and Incomplete Econometric Models, Princeton University Press.

[32] Gravelle, T., Kichian, M., and Morley, J. (2006), "Detecting Shift-contagion in Currency and Bond Markets," Journal of International Economics, 68, 409-23.

[33] Grothe, O., Korniichuk, V., and Manner, H. (2014), "Modeling Multivariate Extreme Events using Self-Exciting Point Processes," Journal of Econometrics, 182, 269-289.

[34] Guidolin, M., and Tam, Y.M. (2013), "A Yield Spread Perspective on the Great Financial Crisis: Break-Point Test Evidence," International Review of Financial Analysis, 26, 18-39.

[35] Guidolin, M., and Timmermann, A. (2008), "International Asset Allocation under Regime Switching, Skew, and Kurtosis Preferences, Review of Financial Studies, 21, 889-935.

[36] Guo, F., Chen, C.R., and Huang, Y.S. (2011), "Markets Contagion during Financial Crisis: A Regime-switching Approach," International Review of Economics and Finance, 20, 95-109.

[37] Hamilton, J.D. (1989), "A New Approach to the Economic Analysis of Nonstationary Time Series and the Business Cycle," Econometrica, 57, 2, 357-84.

[38] Harvey, C. R. and Siddique, A. (2000), "Conditional Skewness in Asset Pricing Tests", The Journal of Finance, 55, 1263-1295.

[39] Ingersoll, J.E. (1987), Theory of Financial Decision Making, Rowman \& Littlefield.

[40] Jeffreys, H. (1961), "Theory of Probability," Clarendon Press, Oxford, Third Edition.

[41] Kaminsky, G.L., and Schmukler, S.L. (1999), "What Triggers Market Jitters?: A Chronicle of The Asian Crisis," Journal of International Money and Finance, 18, $537-560$.

[42] Kasch, M., and Caporin, M. (2013), "Volatility Threshold Dynamic Conditional Correlations: An International Analysis," Journal of Financial Econometrics, 137. 
[43] Kim, C., Piger, J., and Startz, R. (2008), "Estimation of Markov Regime-switching Regression Models with Endogenous switching," Journal of Econometrics, 143, $263-73$.

[44] King, M.A., and Wadhwani, S. (1990), "Transmission of Volatility between Stock Markets," Review of Financial Studies, 3, 1, 5-33.

[45] Kroese, D.P., Taimre, T., and Botev, Z.I. (2011), Handbook of Monte Carlo Methods, John Wiley \& Sons, New York.

[46] Krugman, P. (1998), "It's Baaack: Japan's Slump and the Return of the Liquidity Trap," Brookings Papers on Economic Activity 2, 137-205.

[47] Kyle, A.S., and Xiong, W. (2001), "Contagion as a Wealth Effect," The Journal of Finance LVI, 1401-1440.

[48] Lambert, M., and Hübner, G. (2013), "Comoment Risk and Stock Returns," Journal of Empirical Finance 23, 191-205.

[49] Loisel, O., and Martin, P. (2001), "Coordination, Cooperation, Contagion and Currency Crises," Journal of International Economics, 53, 399-419.

[50] King, M. and Wadhwani, S. (1990), "Transmission of Volatility between Stock Markets," The Review of Financial Studies, 3, 5-33.

[51] Pelletier, D. (2006), "Regime Switching for Dynamic Correlations," Journal of Econometrics, 127, 445-73.

[52] Potì, V., and Wang, D. (2010), "The Coskewness Puzzle," Journal of Banking 86 Finance, 34, 1827-1838.

[53] Robert, C.P. (1995), Simulation of Truncated Normal Variables, Statistics and Computing, 5, 121-25.

[54] Sahu, S.K., Dey, D.K., and Branco, M.D. (2003), "A New Class of Multivariate Skew Distributions with Applications to Bayesian Regression Models," The Canadian Journal of Statistics, 31, 2, 129-50.

[55] Shleifer, A., and Vishny, R.W. (1997), "The Limits of Arbitrage," The Journal of Finance, 52, 35-55.

[56] Smith, D.R. (2007), "Conditional Coskewness and Asset Pricing," Journal of Empirical Finance, 14, 91-119.

[57] Verdinelli, I., and Wasserman, L. (1995), "Computing Bayes Factors Using a Generalization of the Savage-Dickey Density Ratio," Journal of the American Statistical Association, 90, 614-18.

[58] Yuan, K. (2005), "Asymmetric Price Movements and Borrowing Constraints: A Rational Expectations Equilibrium Model of crisis, Contagion, and Confusion," The Journal of Finance, 60, 379-411. 


\section{A The Gibbs Sampler for the RSSN Model}

The details of the MCMC algorithm are as follows. By assuming prior independence between $\beta$ and $\Sigma$, the joint prior density $\pi(\Theta)$ is given by multiplying equations (16) and (17)

$$
\begin{aligned}
\pi(\Theta)= & \prod_{l=0}^{1} \pi\left(\beta_{l}\right) \times \pi\left(\Sigma_{l}\right) \\
\propto & \prod_{l=0}^{1}(2 \pi)^{-\frac{m}{2}}\left|\underline{V}_{\beta}\right|^{-\frac{1}{2}} \exp \left\{-\frac{1}{2}\left(\beta_{l}-\underline{\beta}\right)^{\prime} \underline{V}_{\beta}^{-1}\left(\beta_{l}-\underline{\beta}\right)\right\} \times \\
& \left(2^{-\frac{\tau_{\Sigma} m}{2}} \Gamma_{m}\left(\frac{\underline{\tau} \Sigma}{2}\right)\right)^{-1}\left|\underline{S}_{\Sigma}\right|^{\frac{\tau_{\Sigma}}{2}}\left|\Sigma_{l}\right|^{-\frac{\left(\underline{\tau}_{\Sigma}+m+1\right)}{2}} \exp \left(-\frac{\operatorname{tr}\left(\underline{S}_{\Sigma} \Sigma_{s_{t}}^{-1}\right)}{2}\right) .
\end{aligned}
$$

To calculate the posterior density, the complete-data likelihood function is combined with the joint prior density via Bayes rule. It is given as

$$
\begin{aligned}
\pi(\Theta, Z, s \mid y) \propto & f(y \mid Z, \Theta, s) f(Z) f(s \mid \Theta) \pi(\Theta) \\
= & (2 \pi)^{-\frac{T}{2}} \prod_{t=1}^{T}\left|\Sigma_{s_{t}}\right|^{-\frac{1}{2}} \exp \left\{-\frac{1}{2} \sum_{t=1}^{T}\left[y_{t}-X_{t} \beta_{s_{t}}\right]^{\prime} \Sigma_{s_{t}}^{-1}\left[y_{t}-X_{t} \beta_{s_{t}}\right]\right\} \\
& \times f(Z) f(s \mid \Theta) \pi(\Theta)
\end{aligned}
$$

where $y=\left(y_{1}^{\prime}, \ldots, y_{T}^{\prime}\right)^{\prime}, Z=\left(Z_{1}^{\prime}, \ldots, Z_{T}^{\prime}\right)^{\prime}$ and $s=\left(s_{1}, \ldots, s_{T}\right)^{\prime} . f(Z)$ and $f(s \mid \Theta)$ are provided in equations (9) and (18), respectively. Posterior draws can be obtained using the Gibbs sampler. Specifically, we sequentially draw from $\pi\left(\beta_{0}, \beta_{1} \mid y, Z, \Sigma_{0}, \Sigma_{1}, s\right)$, $\pi\left(Z \mid y, \beta_{0}, \beta_{1}, \Sigma_{0}, \Sigma_{1}, s\right), \pi\left(\Sigma_{0}, \Sigma_{1} \mid y, Z, \beta_{0}, \beta_{1}, s\right)$ and $\pi\left(s \mid y, \beta_{0}, \beta_{1}, \Sigma_{0}, \Sigma_{1}, Z\right)$.

In the first step, $\pi\left(\beta_{l} \mid y, Z, \Sigma, s\right), l=0,1$, is a normal density. To see this, write

$$
\begin{aligned}
\log \pi\left(\beta_{l} \mid y, Z, \Sigma_{0}, \Sigma_{1}, s\right)= & \log f(y \mid Z, \Theta, s)+\log \pi(\Theta)+\text { constant } \\
\propto & -\frac{1}{2}\left(\beta_{l}-\underline{\beta}\right)^{\prime} \underline{V}_{\beta}^{-1}\left(\beta_{l}-\underline{\beta}\right) \\
& -\frac{1}{2} \sum_{t=1}^{T}\left[y_{t}-X_{t} \beta_{s_{t}}\right]^{\prime} \Sigma_{s_{t}}^{-1}\left[y_{t}-X_{t} \beta_{s t}\right], \\
\propto & -\frac{1}{2} \beta_{l}^{\prime}\left(\underline{V}_{\beta}^{-1}+\sum_{t=1}^{T} 1\left(s_{t}=l\right) X_{t}^{\prime} \Sigma_{s_{t}}^{-1} X_{t}\right) \beta_{l} \\
& +\beta_{l}^{\prime}\left[\underline{V}_{\beta}^{-1} \underline{\beta}+\sum_{t=1}^{T} 1\left(s_{t}=l\right) X_{t}^{\prime} \Sigma_{s t}^{-1} y_{t}\right],
\end{aligned}
$$

where

$$
D_{\beta_{l}}=\left(\underline{V}_{\beta}^{-1}+\sum_{t=1}^{T} 1\left(s_{t}=l\right) X_{t}^{\prime} \Sigma_{s_{t}}^{-1} X_{t}\right)^{-1}, \quad \widehat{\beta}_{l}=D_{\beta_{l}}\left[\underline{V}_{\beta}^{-1} \underline{\beta}+\sum_{t=1}^{T} 1\left(s_{t}=l\right) X_{t}^{\prime} \Sigma_{s_{t}}^{-1} y_{t}\right],
$$


which is the kernel of a $q$-variate normal density with mean vector $\widehat{\beta}_{l}$ and covariance matrix $D_{\beta_{l}}$. In other words, $\left(\beta_{l} \mid y, Z, \Sigma_{0}, \Sigma_{1}, s\right) \sim N_{q}\left(\widehat{\beta}_{l}, D_{\beta_{l}}\right)$ with $q=m+k$.

Next, following a similar argument, $\pi(Z \mid y, \Theta, s)$ is a normal density. To see this, using equations (15) and (9)

$$
\begin{aligned}
\log \pi(Z \mid y, \Theta, s)= & \log f(y \mid Z, \Theta, s)+\log f(Z)+\text { constant } \\
\propto & -\frac{1}{2} \sum_{t=1}^{T}\left(y_{t}-\mu_{s_{t}}-\Omega_{s_{t}} Z_{t}\right)^{\prime} \Sigma_{s_{t}}^{-1}\left(y_{t}-\mu_{s_{t}}-\Omega_{s_{t}} Z_{t}\right) \\
& -\frac{1}{2} \sum_{t=1}^{T}\left[Z_{t}-c 1_{m}\right]^{\prime} I_{m}^{-1}\left[Z_{t}-c 1_{m}\right] \\
\propto & -\frac{1}{2} \sum_{t=1}^{T} Z_{t}^{\prime}\left(\Omega_{s_{t}}^{\prime} \Sigma_{s_{t}}^{-1} \Omega_{s_{t}}+I_{m}\right) Z_{t} \\
& +\sum_{t=1}^{T} Z_{t}^{\prime} \Omega_{s_{t}} \Sigma_{s_{t}}^{-1}\left(y_{t}-\mu_{s_{t}}\right)+Z_{t}^{\prime} c 1_{m} .
\end{aligned}
$$

That is, $\left(Z_{t} \mid y, \Theta, s\right) \sim N_{m}\left(\widehat{Z}_{t}, D_{Z_{t}}\right)$ with

$$
D_{Z_{t}}=\left(I_{m}+\Omega_{s_{t}}^{\prime} \Sigma_{s_{t}}^{-1} \Omega_{s_{t}}\right)^{-1}, \quad \widehat{Z}_{t}=D_{Z_{t}}\left(c 1_{m}+\Omega_{s_{t}}^{\prime} \Sigma_{s_{t}}^{-1}\left(y_{t}-\mu_{s_{t}}\right)\right) .
$$

Finally, the log conditional density $\pi\left(\Sigma_{l} \mid y, Z, \beta_{0}, \beta_{1}, s\right)$ is derived and given by

$$
\begin{aligned}
\log \pi\left(\Sigma_{l} \mid y, Z, \beta_{0}, \beta_{1}, s\right)= & \log f(y \mid Z, \Theta, s)+\log \pi(\Theta)+\text { constant } \\
\propto & -\frac{1}{2} \sum_{t=1}^{T}\left[y_{t}-X_{t} \beta_{s_{t}}\right]^{\prime} \Sigma_{s t}^{-1}\left[y_{t}-X_{t} \beta_{s_{t}}\right]-\frac{1}{2} \sum_{t=1}^{T} \log \left|\Sigma_{s_{t}}\right| \\
& -\left(\frac{\underline{\tau} \boldsymbol{\Sigma}+m+1}{2}\right) \log \left|\Sigma_{l}\right|-\frac{1}{2} \operatorname{tr}\left(\underline{S}_{\Sigma} \Sigma_{l}^{-1}\right) \\
\propto & -\left(\frac{\underline{\tau} \boldsymbol{\Sigma}+\sum_{t=1}^{T} 1\left(s_{t}=l\right)+m+1}{2}\right) \log \left|\Sigma_{l}\right| \\
& -\frac{1}{2} \operatorname{tr}\left[\underline{S}_{\Sigma}+\sum_{t=1}^{T} 1\left(s_{t}=l\right)\left(y_{t}-X_{t} \beta_{s_{t}}\right)\left(y_{t}-X_{t} \beta_{s_{t}}\right)^{\prime}\right] \Sigma_{l}^{-1},
\end{aligned}
$$

which is the kernel of an inverse-Wishart distribution. In fact, $\left(\Sigma_{l} \mid y, Z, \beta_{0}, \beta_{1}, s\right) \sim$ $I W\left(\tau_{\Sigma_{l}}, S_{\Sigma_{l}}\right)$, where

$$
\tau_{\Sigma_{l}}=\underline{\tau}_{\Sigma}+\sum_{t=1}^{T} 1\left(s_{t}=l\right), \quad S_{\Sigma_{l}}=\underline{S}_{\Sigma}+\sum_{t=1}^{T} 1\left(s_{t}=l\right)\left(y_{t}-X_{t} \beta_{s_{t}}\right)\left(y_{t}-X_{t} \beta_{s_{t}}\right)^{\prime} .
$$




\section{B The Savage-Dickey Density Ratio}

The Savage-Dickey density ratio of Dickey (1971) is a specific representation of the Bayes factor for comparing nested models. Suppose $\theta=(\psi, \delta)$ is the vector of model parameters in the unrestricted model $M_{u}$. The likelihood and prior for this model are denoted as $f\left(y \mid \psi, \delta, M_{u}\right)$ and $\pi\left(\psi, \delta \mid M_{u}\right)$. Suppose the restricted model $M_{r}$ can be characterized as $\psi=\psi_{0}$, where $\psi_{0}$ is a constant vector, while the parameter vector $\delta$ is free to vary. The likelihood and prior for the restricted model are then denoted as $f\left(y \mid \delta, M_{r}\right)$ and $\pi\left(\delta \mid M_{r}\right)$. Suppose the priors for the two models satisfy

$$
\pi\left(\delta \mid \psi=\psi_{0}, M_{u}\right)=\pi\left(\delta \mid M_{r}\right) .
$$

Under this condition, Verdinelli and Wasserman (1995) show that the Bayes factor comparing $M_{r}$ to $M_{u}$ has the form

$$
B F_{r u}=\frac{p\left(\psi=\psi_{0} \mid y, M_{u}\right)}{p\left(\psi=\psi_{0} \mid M_{u}\right)}
$$

where $p\left(\psi=\psi_{0} \mid y, M_{u}\right)$ and $p\left(\psi=\psi_{0} \mid M_{u}\right)$ are respectively the posterior and prior densities for $\psi$ under the unrestricted model evaluated at the point $\psi_{0}$. Equation (42) is referred to as the Savage-Dickey density ratio.

\section{A Gaussian Copula for Evaluating Probability Densities}

The approach of using a Gaussian copula for approximating a probability density function at a specified point as developed by Geweke (2010) follows. Consider the random vector $u$ with $q$ components

$$
u=\left(u_{1}, \ldots, u_{q}\right) .
$$

Suppose $u^{(1)}, \ldots, u^{(B)}$ are independent and identically distributed draws from the probability density function $p(u)$. Then $p\left(u^{0}\right)$, the density function is evaluated at the point $u^{0}$, which can be approximated using the following steps:

- Step 1: Use a Gaussian kernel to compute the approximations

$$
p_{i}\left(u_{i}\right)=c^{-1} \frac{1}{B} \sum_{b=1}^{B} \phi\left(\frac{u_{i}-u_{i}^{(b)}}{c}\right), \quad P_{i}\left(u_{i}\right)=c^{-1} \frac{1}{B} \sum_{b=1}^{B} \Phi\left(\frac{u_{i}-u_{i}^{(b)}}{c}\right),
$$

for $i=1, \ldots, q$, where $\phi(\cdot)$ and $\Phi(\cdot)$ are respectively the probability density function and cumulative distribution function of

the standard normal distribution. This approximation is computed at each draw, i.e., $u_{i}=u_{i}^{(b)}, b=1, \ldots, B$.

- Step 2: Using this approximation, transform the sampled $u_{i}^{(b)}$ to the normal distribution $w_{i}^{(b)}$,

$$
w_{i}^{(b)}=f_{i}\left(u_{i}^{(b)}\right),
$$


where $f_{i}(\cdot)=\Phi^{-1}\left[P_{i}(\cdot)\right]$, and define

$$
w^{(b)}=\left(w_{1}^{(b)}, \ldots, w_{q}^{(b)}\right)
$$

where $l=1, \ldots, L$.

- Step 3: Approximate the variance as a $(q \times q)$ matrix,

$$
\boldsymbol{\Sigma}=\frac{1}{B} \sum_{b=1}^{B} w^{(b)} w^{(b) \prime} .
$$

since the mean vector $\frac{1}{B} \sum_{b=1}^{B} W^{(b)} \approx 0$.

- Step 4: Estimate the value of function $f_{i}(\cdot)$ at the specified point $u^{0}$ similarly to step 2.

$$
w_{i}^{0}=f_{i}\left(u_{i}^{0}\right), f_{i}^{\prime}\left(u_{i}^{0}\right)
$$

for $i=1, \ldots, q$.

- Step 5: Finally, compute

$$
p\left(u^{0}\right)=\phi\left(w^{0} ; 0, \Sigma\right) \prod_{i=1}^{q} f_{i}^{\prime}\left(u_{i}^{0}\right)
$$

\section{Efficiency of the MCMC Algorithm}

A common diagnostic of MCMC efficiency is the inefficiency factor, defined as

$$
I F=1+2 \sum_{l=1}^{L} \rho(l),
$$

where $\rho(l)$ is degree of correlation, quantified by the autocorrelation function given by

$$
\rho(l)=\frac{1}{T} \sum_{t=1}^{T} X_{t} X_{t-l},
$$

where $X_{t}$ is a sequence for dates $t=1, \ldots, T$ and $l$ represents the lags. $L$ is chosen to be large enough so that the autocorrelation tapers off. To interpret the inefficiency factor, note that independent draws from the posterior would give the inefficiency factor of 1 . Inefficiency factors indicate how many extra draws need to be taken in order to give the results equivalent to independent draws. For instance, if 50,000 draws of a parameter are taken and an inefficiency factor of 100 is found, then the draws are equivalent to 500 independent draws from the posterior. The inefficiency factors for the RSSN model in this paper are contained in Table 8. 
Table 8:

Inefficiency factors of the parameters. The parameters are estimated based on the RSSN model with two regimes denoted by $s_{t}=0$ and $s_{t}=1$.

\begin{tabular}{|c|c|c|c|c|c|c|}
\hline \multirow[t]{2}{*}{ Parameters } & \multicolumn{2}{|c|}{$\mu_{i}$} & \multicolumn{2}{|c|}{$\sum_{i j}$} & \multicolumn{2}{|c|}{$\omega_{i j}$} \\
\hline & $s_{t}=0$ & $s_{t}=1$ & $s_{t}=0$ & $s_{t}=1$ & $s_{t}=0$ & $s_{t}=1$ \\
\hline France & 1.00 & 1.00 & 5.50 & 6.12 & 53.27 & 96.53 \\
\hline Germany & 1.00 & 1.00 & 5.74 & 5.97 & 28.74 & 89.57 \\
\hline Greece & 1.00 & 1.00 & 5.15 & 34.81 & 109.98 & 45.40 \\
\hline Italy & 1.00 & 1.00 & 5.57 & 7.07 & 57.06 & 100.80 \\
\hline US & 1.00 & 1.11 & 3.99 & 27.50 & 7.50 & 67.65 \\
\hline France-Germany & - & - & 5.21 & 16.19 & 5.36 & 80.08 \\
\hline France-Greece & - & - & 5.05 & 25.69 & 65.10 & 34.40 \\
\hline France-Italy & - & - & 5.75 & 10.86 & 24.69 & 122.74 \\
\hline France-US & - & - & 3.69 & 35.94 & 6.48 & 63.58 \\
\hline Germany-Greece & - & - & 4.59 & 3.27 & 116.85 & 5.04 \\
\hline Germany-Italy & - & - & 5.01 & 29.28 & 106.81 & 61.96 \\
\hline Germany-US & - & - & 3.69 & 5.70 & 20.62 & 11.15 \\
\hline Greece-Italy & - & - & 5.29 & 28.02 & 36.98 & 130.78 \\
\hline Greece-US & - & - & 3.87 & 38.24 & 5.02 & 71.44 \\
\hline Italy-US & - & - & 3.12 & 20.20 & 6.79 & 31.77 \\
\hline
\end{tabular}

